\title{
Asymmetric Responses to Earnings News: A Case for Ambiguity
}

\section{Christopher D. Williams}

A dissertation submitted to the faculty of the University of North Carolina at Chapel Hill in partial fulfillment of the requirements for the degree of Doctor of Philosophy in the Kenan-Flagler Business School.

Chapel Hill

2009

Approved by:

Robert M. Bushman

Wayne R. Landsman

Jennifer Conrad

Mark Lang

Steve Stubben 


\begin{abstract}
Christopher D. Williams: Asymmetric Responses to Earnings News: A Case for Ambiguity
\end{abstract}

(Under the direction of Robert M. Bushman and Wayne R. Landsman)

In this paper I empirically investigate whether investors change the way they respond to earnings releases following changes in "ambiguity" in a manner consistent with extant research that distinguishes risk from ambiguity. With risk, decision-makers possess known probabilities and formulate unique prior distributions over all possible outcomes. In contrast, with ambiguity, decision-makers possess incomplete knowledge about probabilities and are unable to formulate priors over all possible outcomes. Existing theoretical research supports the hypothesis that investors respond differentially to good versus bad news information releases when confronted with ambiguity. As a proxy for ambiguity I use the volatility index (VIX). I provide evidence that following increases in VIX investors respond asymmetrically, weighting bad earnings news more than good earnings news. Conversely, following a decrease in VIX investors respond symmetrically to good and bad earnings news. Results are robust to consideration of both risk and investor sentiment explanations. I also document that the effect of ambiguity is intensified for firms with a high systematic component to earnings, and is mitigated for firms with high trading volume over the event window. This study provides large sample, empirical evidence that ambiguity changes how market participants process earnings information. 
To Joung Suk, Chris, Stephanie and Breanna 


\section{ACKNOWLEDGEMENTS}

In completing this work I am indebted to the following people for their helpful comments and encouragement: Robert Bushman (co-chair), Wayne Landsman (co-chair), Jennifer Conrad, Mark Lang, Steve Stubben, Jeff Abarbanell, Dan Amiram, Rick Antle, Ryan Ball, Phil Berger, Scott Dyreng, Jennifer Francis, Jeremiah Green, Lars Hansen, Raffi Indjejikian, Ed Maydew, Venky Nagar, Ed Owens, Luca Rigotti, Katherine Schipper, Cathy Schrand, William Schwert, Doug Skinner, Abbie Smith, Cliff Smith, Shyam Sunder, Peter Wysocki, Ro Verrecchia, Jerry Zimmerman and workshop participants at the University of North Carolina at Chapel Hill, Duke, the Ohio State, University of Michigan, M.I.T., Wharton, University of Chicago, U.S.C., Yale, University of Rochester and participants at the 2008 Brigham Young University Accounting Research Symposium. I am also grateful to my parents and I am especially grateful to my wife for all of her support and extraordinary courage. 


\section{TABLE OF CONTENTS}

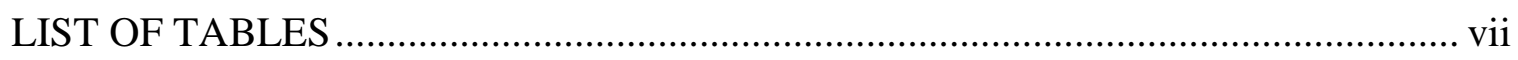

LIST OF FIGURES ...................................................................................... viii

\section{CHAPTER}

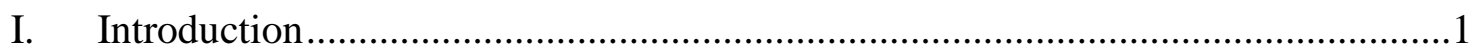

II. Conceptual Framework and Related Literature ...............................................9

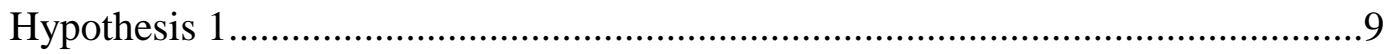

Levels verses Changes, the Empirical Proxy for Ambiguity and H1* .................12

Ambiguity, Participation and Trading Volume ..............................................16

Market Response to Earnings News ............................................................18

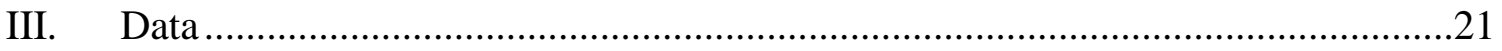

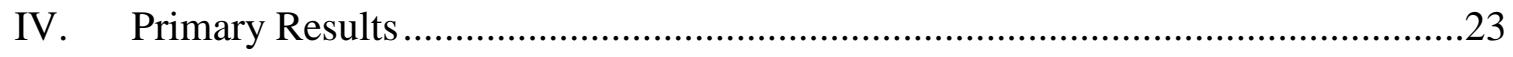

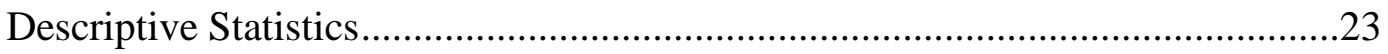

H1* - Asymmetric Responses to Changes in VIX (Ambiguity)..........................24

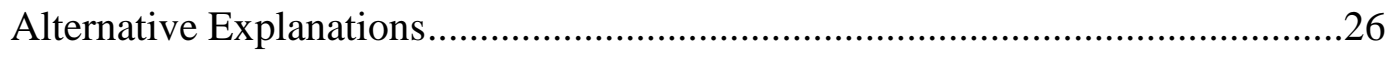

Leverage and Feedback Effects ............................................................27

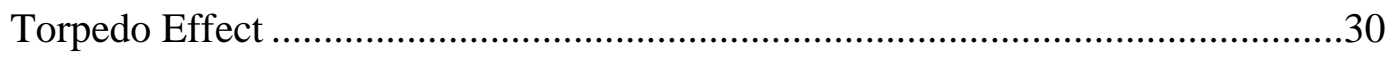

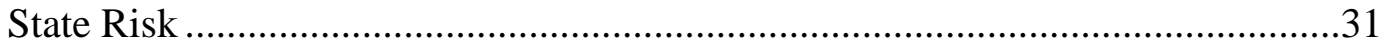




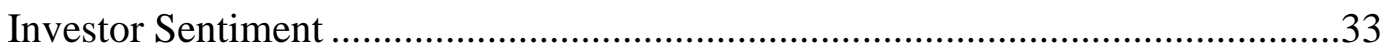

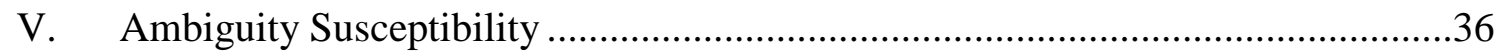

VI. Trading Volume and the Bid-Ask Spread....................................................40

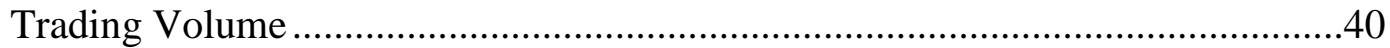

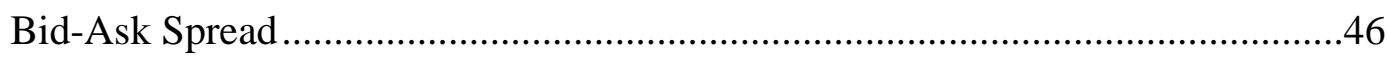

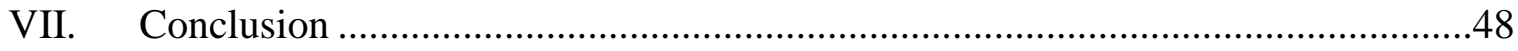

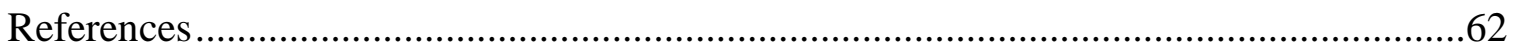




\section{LIST OF TABLES}

Table

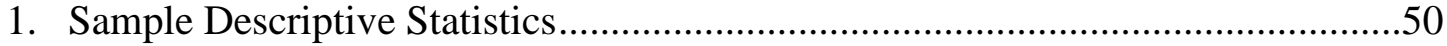

2. Investors’ Asymmetric Response to Earnings Surprise under Ambiguity .............51

3. Alternative Explanations for Investors Asymmetric Response to Earnings Surprises under Ambiguity: Leverage and Feedback Effects.

4. Alternative Explanations for Investors’ Asymmetric Response to Earnings Surprise under Ambiguity: Risk and Sentiment

5. Ambiguity Susceptibility and Investors’ Asymmetric Response to Earnings Surprise under Ambiguity: Earnings Beta

6. Ambiguity Susceptibility and Investors’ Asymmetric Response to Earnings Surprise under Ambiguity: VIX Beta

7. The Examination of the effects of Information (Abnormal Firm Volume) on Investors’ asymmetric Response to Earnings Surprise under Ambiguity

8. The Examination of the Effects of Information (Abnormal Market Volume) on Investors’ Asymmetric Response to Earnings Surprise under Ambiguity ....

9. The Effect of Ambiguity on the Asymmetric Response by the Market by Volume and Earnings Process Characteristics

10. Increases in Ambiguity and the Effect on the Bid-Ask Spread .59 


\section{LIST OF FIGURES}

Figure

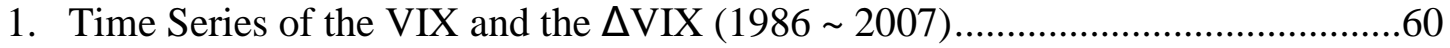

2. Plot of GOODNEWS and BADNEWS Coefficients across Quintiles of $\triangle$ VIX .....61 


\section{Introduction}

In this paper, I investigate the role of ambiguity in shaping the responses of stock market participants to firm-specific information releases. Beginning with Knight (1921) and later with Ellsberg (1961), a substantial body of literature in economics, finance, and decision theory posits a fundamental distinction between risk and ambiguity, and examines implications of this distinction for economic decision-making. In settings characterized by risk, decision-makers possess known probabilities (objective or subjective) and can formulate unique prior distributions over all possible outcomes. ${ }^{1}$ In contrast, in settings with ambiguity, decision-makers possess incomplete knowledge about probabilities and are unable or unwilling to formulate a unique prior over all possible outcomes. ${ }^{2}$ I contribute to the existing literature by empirically examining whether investors process information differently following increases in ambiguity than following decreases in ambiguity. I provide large sample evidence that following increases in ambiguity, investors respond asymmetrically to bad and good news earnings announcements, weighting bad news more than the good news. In contrast, decreases in ambiguity are followed by symmetric responses to bad and good news.

\footnotetext{
${ }^{1}$ That is, decision-makers are presumed to have preferences that satisfy the Savage (1954) axioms, implying that they maximize expected utility with respect to unique prior beliefs.

${ }^{2}$ In a classic paper, Ellsberg (1961) provides experimental evidence that the distinction between risk and ambiguity is behaviorally meaningful, showing that people treat ambiguous bets differently from risky bets (i.e., The Ellsberg Paradox, see appendix A for further details). In this paper I use the term ambiguity to characterize settings where there is incomplete knowledge about probabilities. Other terms commonly used in the literature are uncertainty, model uncertainty, and Knightian uncertainty.
} 
Ambiguity can be conceptualized by assuming that a decision-maker is endowed with a set of probability distributions over possible outcomes, and that he is unable or unwilling to assess a unique prior over the multiple probability distributions in the set. In such a case, ambiguity is represented as a multiplicity of possible probability distributions that cannot be reduced to a singleton because of missing information to the agent that is relevant. ${ }^{3}$ In a capital markets setting, such ambiguity could result from shocks to the economy that cause investors to become uncertain or fearful as to whether they are using an incorrect model to evaluate the future. For example, the behavior of market participants during the recent credit crisis can be interpreted in an ambiguity framework (e.g., Easley and O’Hara (2008)). ${ }^{4}$

The economic logic underpinning my predictions derives from Gilboa and Schmeidler (1989), who axiomatize a maxmin expected utility theory in which a decision-maker possessing a set of distributions chooses an action that maximizes expected utility given the probability weights that represent the worst case scenario from

\footnotetext{
${ }^{3}$ See Camerer and Weber (1992) and Frisch and Baron (1988) for further discussion of ambiguity from a general, decision theoretic perspective.

${ }^{4}$ The following quotes are instructive here: "There has been something deeply disconcerting about the negotiations of the past few days in Washington to bail out the U.S. financial system: The best and brightest of policy and economic elites have seemed out of their depth. Congressional leaders, senior administration officials, top bankers and economists, even the Chairman of the Federal Reserve admit they don't fully understand what's happening or what to do...And so, what once seemed like manageable risk has mutated into unbounded uncertainty."

-Thomas Homer-Dixon, The Globe and Mail; "It just is something we haven't seen in our lifetimes, so it's hard to tell exactly where we are." -Tom Forester, Associated Press Newswire, referring to the financial crises of 2008.
} 
the entire set of potential probabilities. ${ }^{5}$ Under this theory, ambiguity induces ambiguity averse agents to act very cautiously, or even pessimistically, and choose the worst-case beliefs from the set of possible probability measures. As I describe in detail next, such behavior can lead investors to respond differentially to good versus bad news information releases when confronted with ambiguity.

In this paper, I hypothesize that following increases in ambiguity, stock price reactions to earnings releases reflect investors weighting bad news earnings more heavily than good news earnings, and following decreases in ambiguity, stock price reactions reflect investors symmetrically weighting bad and good news earnings. ${ }^{6}$ Two recent theories are particularly pertinent to the formulation of my hypothesis.

First, Epstein and Schneider (2008) model the possibility that financial market participants have incomplete information with respect to the precision of future information signals. Investors know that true precision is contained in a set of possible precisions, but cannot assess a unique prior over this set. The wider the range of possible signal precisions contained in the investor's set, the greater the ambiguity. With respect to earnings releases, such ambiguity could result from a lack of confidence on the part of investors in their ability to interpret the implications of current earnings signals for future cash flows in an uncertain environment. For example, investors may become uncertain about how to interpret earnings from mark-to-market accounting adjustments in chaotic asset markets. Now, following maxmin logic, investors optimize expected utility given

\footnotetext{
${ }^{5}$ Epstein and Schneider (2003) extend Gilboa and Schmeidler (1989) to an inter-temporal setting. Ahn (2008) points out that under the maxmin expected utility theory ambiguity is subjective ambiguity in reference to Savage (1954). Ahn (2008) and others model a form of objective ambiguity

${ }^{6}$ Throughout the paper I use 'changes in ambiguity' and 'ambiguity shock' interchangeably.
} 
the worst case precision from the set of possible precisions. Epstein and Schneider (2008) show that if investors observe a bad news signal, they assume the signal's precision is the highest possible in their subjective set, and react strongly by placing more weight on the high precision signal. On the other hand, if the signal is good news, they assume the lowest possible precision in their set, generating a muted response to the low precision signal.

Second, consider the following quote from Hansen and Sargent (2008): “A pessimist thinks that good news is temporary but that bad news will endure.” This quote suggests the possibility that ambiguity can affect the way investors assess the implications of current earnings for the future wealth generating process. Hansen and Sargent (2008) model investors as having incomplete information about the underlying wealth-creating process, and as a result they face a range of possible models with differing persistence properties that cannot be statistically separated by an econometrician given a finite sample. Asymmetric responses to good and bad news is driven by the way investors cope with uncertainty about the competing models of wealth creation. In Hansen and Sargent (2008), negative signals lead ambiguity-averse investors to slant their probability assessments towards the most pessimistic underlying model where such negative shocks are persistent, while good news signals push assessments towards a model with low persistence. Building on this economic logic, if ambiguity-averse investors observe a bad news earnings signal during times of significant ambiguity, they pessimistically slant towards the worst-case model with the highest persistence, and thus react strongly to the signal as they assess such bad news to have significant, ongoing 
effects. On the other hand, if the signal is good news, they move towards a model where the persistence of the signal is low, and respond weakly to the signal.

Before proceeding, I want to stress that empirical research on ambiguity in capital markets is in its infancy, and my hypotheses are necessarily exploratory in nature. Thus, while I am not able to distinguish between these two particular theories at this time, I argue that these theories provide two intuitive and plausible mechanisms that could drive the predicted asymmetric responses to bad and good news signals, and as such represent a useful point of departure for empirical explorations of ambiguity.

Central to my empirical design is a measure of changes in ambiguity prior to earnings announcements. While conceptually the level of ambiguity and changes in ambiguity lead to similar predictions in a one period model, sustained levels of ambiguity lead to different predictions in a multi-period model. Epstein and Schneider (2008) point out the importance of ambiguity shocks when empirically studying ambiguity, because agents are in novel environments. Therefore, I measure changes in ambiguity using changes in the volatility index (VIX) over the two-day window prior to the earnings announcement window. VIX is computed daily by the Chicago Board Options Exchange and is the weighted average of implied 30 day volatility of the S\&P 100 stocks as reflected in index option prices. ${ }^{7}$ Although it is not obvious how to empirically measure ambiguity, I argue that VIX is an important and useful starting point. A recent paper by Drechsler (2008) posits and provides evidence that VIX contains an important ambiguityrelated component. The essence of his model is that options provide investors with a

\footnotetext{
${ }^{7}$ Although throughout the paper I refer to VIX as the implied volatility of the S\&P 100, the actual ticker of the index is the VXO. The true VIX is a market free model of implied volatility on the S\&P 500. I use the prior measure because the time series is longer, but my results are not sensitive to the use of the true VIX.
} 
natural protection against uncertainty (ambiguity) and as a result, time-variation in uncertainty concerns is strongly reflected in option premia, and thus in VIX. An alternative measure of ambiguity, the dispersion in macro forecasts, is used in Anderson et al. (2008). However, as shown by Drechsler (2008), the dispersion of macro forecasts is highly correlated with VIX. It is also the case that macro forecasts dispersion is not available on a daily basis, which is a key element of my empirical design.

My empirical design focuses on the three-day return window centered on quarterly earnings announcement dates. I estimate the elasticity of stock returns to negative and positive earnings news, conditioning on whether VIX increased or decreased in the two days just prior to the earnings announcement window. The strategy is to test for differences in the magnitude of bad news coefficients relative to good news coefficients after increases and decreases in VIX.

Using quarterly earnings announcements from 1986-2006, I find evidence consistent with changes in ambiguity affecting investor responses to information releases. Specifically, immediately following an increase (decrease) in VIX there is an asymmetric (symmetric) response to quarterly earnings news. Increases (decreases) in VIX result in larger (equal) responses to bad news relative to good news.

I further examine whether the documented asymmetry (symmetry) following increases (decreases) in VIX is a picking up another existing phenomenon or is an orthogonal phenomenon. I specifically test to see if the result is robust to leverage effects/volatility feedback effects (Black, 1976; Christie, 1984; Schwert, 1989, Bekaert and $\mathrm{Wu}, 2000$ ), the market-to-book effect (i.e., the 'torpedo effect') (Skinner and Sloan, 
2002), investor sentiment (Baker and Wurgler, 2006; Livnat and Petrovits, 2008; Mian and Sankaraguruswamy, 2008) or investor perceptions of the state of the economy (Veronesi, 1999; Conrad, Cornell and Landsman, 2002).

I next investigate the possibility that some firms are more susceptible to the effects of ambiguity than others. Given that VIX is a macro-economic variable, I investigate the extent to which the effect of ambiguity (i.e., higher response to bad news relative to good news) varies cross-sectionally with two measures of the firm's connections with macro fluctuations. I consider both the extent to which firms' earnings co-vary with aggregate market earnings, and the extent to which stock returns co-vary with changes in VIX. I find that the effects of increases in ambiguity are more pronounced for firms with high earnings betas, and for firms whose returns are most sensitive to changes in VIX.

Finally, I explore the interplay of ambiguity with trading volume and bid-ask spreads. The literature suggests a connection between ambiguity and both trading volume and bid-ask spreads (Bewley, 2002; Dow and Werlang, 1992; Epstein and Schneider, 2007 and Easley and O’Hara, 2008, Easley and O’Hara, 2009). I document that the asymmetric responses to bad earnings news relative to good news following an increase in VIX are much stronger for firms with relatively low abnormal trading volume during the earnings announcement window. This is consistent with Epstein and Schneider (2007) who show in an inter-temporal portfolio choice model that an increase in ambiguity (i.e., an increase in the set of possible distributions) leads investors to trend away from stock 
market participation. I also find that after controlling for the earnings surprise, there is a substantial increase in bid-ask spreads following increases in VIX.).

Beginning with Ball and Brown (1968) and Beaver (1968), accounting research has studied how the market responds to accounting information (Atiase, 1985, 1987; Collins and Kothari, 1989; Easton and Zmijewski, 1989; Freeman and Tse, 1992; Kormendi and Lipe, 1989; Lang, 1992; Subramanyam, 1996; see Kothari (2001) for a review). Typically, this stream of research assumes that investors' preferences conform to the standard subjective expected utility theory of Savage (1954). This paper contributes to this literature by providing empirical evidence that investors on average appear to make a distinction between risk and ambiguity in the context of earnings announcements, investors are averse to ambiguity and that investor preferences do not conform to those of Savage (1954). It also provides important insight into furthering our understanding of how the market's response to earnings information is a function of the context in which the information is received.

The remainder of the paper is organized as follows; section 2 develops the conceptual framework on the effects of ambiguity on decision making. Section 3 explains the data. Section 4 reports the primary results and test for alternative explanations. Section 5 examines cross-sectional variation in ambiguity susceptibility. Section 6 examines the interplay between ambiguity and trading volume and the effects of ambiguity on bid-ask spread. Section 7 concludes the study. 


\section{Conceptual Framework and Related Literature}

\subsection{Hypothesis 1}

As noted in the introduction, I hypothesize that following increases in ambiguity, stock price reactions to earnings releases weight bad news earnings more heavily than good news earnings, and following decreases in ambiguity, stock price reactions symmetrically weight bad and good news earnings. The economic logic underpinning this hypothesis is extracted from two recent papers.

First, Epstein and Schneider (2008) consider the possibility that investors know that the true precision of future information signals is contained in a set of possible precisions, but cannot assess priors over this set. The wider the range of possible signal precisions contained in the investor's set, the greater the ambiguity. To be concrete, consider that $v$ is a parameter that investors want to learn, but that they only observe the noisy signal $s=v+\epsilon$. The key to the ambiguity notion is the noise term $\epsilon \sim N\left(0, \sigma_{\epsilon}^{2}\right)$, where $\sigma_{\epsilon}^{2} \in\left[\underline{\sigma}_{\epsilon}^{2}, \bar{\sigma}_{\epsilon}^{2}\right]$. That is, the signal $s$ is related to the parameter $v$ by a family of likelihoods characterized by a range of precisions $\left[1 / \bar{\sigma}_{\epsilon}^{2}, 1 / \underline{\sigma}_{\epsilon}^{2}\right]$. Following Gilboa and Schmeidler (1989) and Epstein and Schneider (2003), an ambiguity-averse agent will behave as if he maximizes expected utility under a worst-case belief that is chosen from a set of conditional probabilities. That is, agents evaluate any action using the conditional probability that minimizes the utility of that action. In the model of Epstein and Schneider (2008), when an ambiguous signal conveys bad news, the worst case is that the 
signal is very reliable (i.e., precision $=1 / \underline{\sigma}_{\epsilon}^{2}$ ) and the investor responds strongly, and vice versa for good signals (i.e., precision $=1 / \bar{\sigma}_{\epsilon}^{2}$ ). ${ }^{8}$

Ambiguity with respect to the precision of earnings releases can potentially result when an economic shock creates a lack of confidence by investors resulting in a reduction of investor confidence in interpreting the implications of earnings signals (e.g., signal interpretation a la Kim and Verrecchia (1994)). For example, consider the model of Kim and Verrecchia (1994). While it is not modeled in Epstein and Schneider (2008), an alternative formulation that also supports my hypothesis is to assume that an economic shock creates ambiguity with respect to the volatility of the fundamentals. ${ }^{9}$ That is, rather than ambiguity with respect to precision of the signal, allow for ambiguity with respect to the variance of the fundamentals. In terms of the example in the previous paragraph, let the fundamental $v \sim N\left(0, \sigma_{v}^{2}\right)$, where $\sigma_{v}^{2} \in\left[\underline{\sigma}_{v}^{2}, \bar{\sigma}_{v}^{2}\right]$. Now, recalling $E[v \mid s]=\frac{\sigma_{v}^{2}}{\sigma_{\varepsilon}^{2}+\sigma_{v}^{2}} * s$ (see footnote 8), if $s<0$, the most pessimistic response is achieved by assuming that $\sigma_{v}^{2}=\bar{\sigma}_{v}^{2}$, which makes the coefficient on $s$ as high as possible. The assumption that $\sigma_{v}^{2}=\bar{\sigma}_{v}^{2}$ is equivalent to assuming that the signal is very informative with respect to the fundamentals, $v$ (and vice versa for $s>0$ where $\sigma_{v}^{2}=\underline{\sigma}_{v}^{2}$ ).

The second basis for my hypothesis is consistent with the following quote from Hansen and Sargent (2008): “A pessimist thinks that good news is temporary but that bad

${ }^{8}$ To see this simply, assume $E[s]=0, \operatorname{cov}(v, \epsilon)=0$ and note that $E[v \mid s]=\frac{\operatorname{cov}(v, s)}{\operatorname{var}(s)} * s=\frac{\sigma_{v}^{2}}{\sigma_{\epsilon}^{2}+\sigma_{v}^{2}} * s$. If $s<0$, the most pessimistic response is achieved by assuming that $\sigma_{s}^{2}=\underline{\sigma_{s}^{2}}$, which makes the coefficient on $s$ as high as possible, and if $s>0$, the most pessimistic response is achieved by assuming that $\sigma_{s}^{2}=\overline{\sigma_{s}^{2}}$ which makes the coefficient on $s$ as low as possible

${ }^{9}$ Epstein and Schneider (2008) allow for ambiguity with respect to the mean of the fundamentals, not the volatility. See also Caskey (2008) on this point. 
news will endure.” Hansen and Sargent (2008) model a representative consumer who evaluates consumption streams in light of model selection and parameter estimation problems. The consumer is uncertain as to which model governs future consumption growth. One model exhibits persistence in information shocks, while the other model does not. The arrival of signals induces the consumer to alter his posterior distribution over models and parameters. However, due to specification doubts (ambiguity), the consumer updates his priors over models by slanting probabilities pessimistically. That is, negative signals lead a cautious consumer to slant his probability assessments towards the most pessimistic underlying model where such negative shocks are persistent, while good news signals push assessments towards a model with low persistence. While this is a representative consumer model focused on the macro economy and thus does not speak directly to firm-specific earnings announcements, the possibility that macro shocks could cause investors to be uncertain about the persistence of current earnings seems at least plausible, especially if the firm's underlying wealth generating process is highly connected to the macro economy. I address this conjecture in Section 5. If investors observe a bad news earnings signal, they pessimistically slant towards the worst-case model with the highest persistence and react strongly to the signal. On the other hand, if the signal is good news, they move towards a model where the persistence of the signal is low and so respond weakly to the signal.

Given the above arguments and motivation I formalize my predictions in the following hypothesis stated in the null:

H1a: Ambiguity causes stock price responses to be symmetric for negative and positive unexpected earnings. 
H1b: The lack of ambiguity causes stock price responses to be symmetric for negative and positive unexpected earnings.

Before preceding it is important make two points, first I want to point out that the theory literature on ambiguity is evolving, and that there exists models of ambiguity that do not lead to an asymmetric response to bad and good news signals. In a recent paper, Caskey (2008) models ambiguity in information signals using an alternative formulation to that of Epstein and Schneider (2008). Caskey (2008) models ambiguity-averse preferences using Klibanoff, Marinacci, and Mukerji's (2005) characterization of ambiguity aversion, and assumes that investors face ambiguity with respect to the unknown mean of the noise term in the information signal. In this model, prices do not respond asymmetrically to good and bad news signals. Ultimately, empirical evidence is needed to more fully understand the role, if any, of ambiguity in capital markets. I contribute to this process with my empirical analysis. Second, the above hypotheses are stated in a levels framework, yet as mentioned in the introduction I test a changes specification. The next section explains my both my motivation for the changes specification and the restated hypotheses.

\subsection{Level verses Changes, the Empirical Proxy for Ambiguity and H1*}

Perhaps one of the largest obstacles preventing empirical research from investigating the effects of ambiguity on capital markets is the availability of proxies for ambiguity. Anderson et al. (2008) use as a proxy for variation in ambiguity the quarterly dispersion in professional forecasters. However I do not use this measure because to whatever degree it measure the ambiguity in the market it does so in an untimely manner 
making it hard to quantify on a given day during the interim investors' decision environment.

Drechsler (2008) posits and provides evidence that VIX contains an important ambiguity-related component. Key to the study is the empirical observation that index options are priced with positive premia, implying that buyers of index options pay a large hedging premium. ${ }^{10}$ Drechsler (2008) analyzes and calibrates a general equilibrium model incorporating time-varying Knightian uncertainty regarding economic fundamentals. ${ }^{11}$ The model shows that options provide investors with a natural protection against ambiguity, and as a result, time-variation in uncertainty is strongly reflected in option premia and in VIX. ${ }^{12}$ More importantly for my study Drechsler (2008) shows the dispersion in macro forecasts are highly correlated with the level of VIX. ${ }^{13}$ The extent to which VIX actually captures the underlying ambiguity construct is an open question. I argue, however, that it is very useful starting point for empirical investigations of the extent to which ambiguity affects observable decision making.

\footnotetext{
${ }^{10}$ A measure of this premium is the variance premium, which is defined as the difference between the option-implied (VIX), and the statistical (true) expectation of one-month return variance, for which a typical proxy is realized return volatility that is computed by using five minute trading intervals over the course of the month.

${ }^{11}$ For this paper I use the change in VIX instead of the premium as in Drechsler (2008). Ex ante the choice of VIX unadjusted for realized volatility does not provide any obvious bias, it does however increase the level of noise in my measure. To mitigate the possibility that changes in VIX do not capture some other phenomenon, I conduct robustness tests that include investor sentiment and risk.

${ }^{12}$ An alternative argument for the use of VIX as a proxy for ambiguity is one can think of ambiguity as being “...created by missing information that is relevant and could be known” (Frisch and Baron, 1988). One of the byproducts of such a situation is that not knowing the information is both upsetting and scary (Camerer and Weber, 1992). Another name for the VIX is 'the fear index', and recent anecdotal evidence during the credit crisis suggests that investors pay attention to the VIX when they are fearful and uncertain.

${ }^{13}$ Andersen et al. (2008) suggests that in addition to the dispersion of macro forecasters, firm specific forecast dispersion may also provide a firm specific measure of ambiguity. To the extent it is correlated with macro ambiguity it may have implications for asset pricing. Untabulated findings indicate that changes in VIX are positively correlated with analysts' earnings forecast dispersion.
} 
Unlike the dispersion in macro forecast the VIX is computed daily by the Chicago Board Options Exchange and is the weighted average of implied 30 day volatility of the S\&P 100 stocks as reflected in index option prices (see Whaley (2000) for further details). In Figure 1 panel A, the times series of the VIX index is plotted over my sample period. Descriptively the VIX index is always strictly greater than zero with a mean over the period of $20.37 \%$ and a standard deviation of $8.11 \%$. An additional important and well documented property of the VIX is that it is persistent. Empirically the level of the VIX has shown to have a large first-order autocorrelation of approximately 95\%.

While the use of the VIX allows one more frequent intervals of measurement the use of the level of VIX is problematic for the purposes of my study. One of the key propositions put forth in the above section is that the same information can be processed differently depending on whether the environment is characterized by ambiguity or risk. It is also reasonable to assume that ambiguity would affect more than investors decision making process but also the signal generating process. While the response to ambiguity is immediate for individual agents (i.e., investors, managers, analysts) the accounting information system will capture the effects of ambiguity with a lag. This means not only can the signal be affected by ambiguity but also the response to the information at the time of the announcement depending on the interim information flows.

As documented above the level of the VIX is persistent and therefore any given level could have existed prior to the measurement for a significant duration of time thereby influencing the signal generation process. Prior literature (Heath and Tversky, 1991; Epstein and Schneider, 2007; 2008) suggest that often the effects of ambiguity as 
most pronounced when there is an ambiguity shock that forces decision makers to make decisions in an unfamiliar environment. Such shocks to decision makers would be unpredictable. While the level of VIX has a high autocorrelation the change in VIX does not. Figure 1 panel b plots the two-day changes in VIX over the sample period. The mean of the series is 0.0018 with a standard deviation of $3.16 \%$. More importantly the firstorder autocorrelation of the change in VIX is basically zero (less than 0.0001). Using two-day changes in the VIX allows me to shocks at high frequency, in addition I am able to hold the signal relatively constant because I can measure the shock after the earnings reports are generated but before the public release of the information.

As a partitioning variable in my study I use the two-day change in the VIX immediately preceding the announcement window, more specifically I partition the data into increases and decreases in the VIX. As shown above increases/decreases in the VIX have no autocorrelation but does splitting on increases and decreases accomplish the goal of holding the signal constant. Table 1 shows the descriptive statistics for firms in the increase in VIX $\left(\Delta V I X^{+}\right)$and decrease in VIX $\left(\Delta V I X^{-}\right)$. The first thing that is evident is that $\Delta V I X^{+}$sample is for the most part not significantly different from the $\Delta V I X^{-}$sample, more importantly bad news (BadNews) and good news (GoodNews) is both not statistically (or economically) different from each other. ${ }^{14}$

Conceptually both levels and changes in ambiguity give similar predictions, specifically increases in ambiguity will lead to asymmetry in responses to good and bad news, and decreases in ambiguity will lead to less asymmetry or even symmetry (as

\footnotetext{
${ }^{14}$ In unreported results the same descriptive statistics are run splitting on median level of VIX. Consistent with my argument with the exception of Ret all other characteristics are both statistically (at the $<0.001$ level) and economically different across the low and high VIX groups.
} 
opposed to strict symmetry) in responses to good and bad news holding the level of ambiguity constant. While ideally I would like a measure that would allow me to turn on and off ambiguity. In considering the trade-offs between using a changes vs. levels specification, the benefit of being able to control the inputs in the decision process in a change specification seems a more powerful specification give the imperfections in the empirical measure. Therefore I modify H1a and H1b in terms of changes, specifically I put forth and test the following stated again in the null:

H1a*: Increase is Ambiguity causes stock price responses to be symmetric for negative and positive unexpected earnings.

H1b*: Decreases in ambiguity causes stock price responses to be symmetric for negative and positive unexpected earnings.

\subsection{Ambiguity, Participation and Trading Volume}

Finally, it is useful to ask whether the asymmetric reactions to good and bad news predicted by ambiguity represent trading opportunities that are left unexploited. In the models of Epstein and Schneider (2008), Hansen and Sargent (2008) and others, there are only ambiguity-averse traders in the model. Since all traders are uncertain about the probability structure of the model, there is no one to take advantage of "over-reactions" or "under-reactions" to information signals. It is presumed in these models that no market participant is able to resolve ambiguity with a finite sample of past observations, so everyone is in the same situation. In contrast Caskey (2008) and Easley and O'Hara (2009) allows for both ambiguity-averse and Bayesian (or ambiguity neutral) traders simultaneously. In Caskey (2008), ambiguity-averse traders choose aggregated 
information to mitigate ambiguity, while Bayesian traders choose disaggregated signals. In equilibrium, the better informed Bayesians do exploit ambiguity-averse traders, but the gain to ambiguity-aversion from ambiguity mitigation outweighs the losses to better informed Bayesians. Easley and O’Hara (2009) take a different approach by using the non-participation results of Dow and Werlang (1992). Easley and O’Hara (2009) show that when there is non-participation by ambiguity averse investor the Bayesian cannot fully eliminate the pricing effects of the ambiguity averse investors because arbitrage cannot correct the non-participation effect of risk-sharing.

In section 6 of my paper, I explore this issue by examining the relation between ambiguity and trading volume. A number of papers in the literature show that ambiguity reduces market participation, or trading, by ambiguity-averse investors (e.g., Dow and Werlang, 1992; Epstein and Schneider, 2007; and Easley and O’Hara, 2008, Easley and O’Hara, 2009). In structuring my empirical design, I conceptualize ambiguity as being driven by missing information (about probabilities, models, etc.). If no traders are in possession of the missing information and all traders are ambiguity-averse, then there is no one available to arbitrage, and I conjecture that following increases in ambiguity, firms with relatively low trading volume will have the most pronounced asymmetric responses to bad versus good news. In contrast, if some (ambiguity-averse) traders are able to find the missing information following an increase in ambiguity, they will trade on this information and drive the ambiguity effects out. Alternatively in a Easley and O'Hara (2009) world if there currently exists a state of nonparticipation the discovery of information that resolves the ambiguity eliminates the ambiguity effects because it bring 
ambiguity averse investor back into the market and increases the risk-sharing. Either way, I conjecture that following increases in ambiguity, firms with relatively high trading volume will have muted asymmetric responses to bad versus good news.

\subsection{Market Response to Earnings News}

The primary research design to capture the differential responses to good and bad earnings news is adopted from Conrad et al. (2002).

$$
\text { Ret }=\beta_{o}+\beta_{1} \text { BADNEWS }+\beta_{2} \text { GOODNEWS }+\varepsilon_{i t}
$$

where Ret is equal to the three day $(t-1$ to $t+1)$ cumulative market adjusted return for the firm and $t$ is the reported earnings announcement date. BADNEWS and GOODNEWS are constructed by first computing the firm's seasonally adjusted unexpected earnings (UE) scaled by average total assets. BADNEWS (GOODNEWS) is equal to UE when UE $<(>) 0$ and 0 otherwise. Interpretation of the coefficient $\beta_{N U E}$ in (1) is the market's response to bad news and $\beta_{P U E}$ is the market's response to good news.

To test for the effects of changes in ambiguity I measure changes in VIX just prior to the release of the earnings information. I estimate Model (1) for both increases in VIX $\left(\Delta V I X^{+}\right)$and decreases in VIX $\left(\Delta V I X^{-}\right)$to test whether differential responses to bad and good earnings news by the market varies with changes in the sign of ambiguity. To examine the asymmetry in responses I use three different methods. In the first test I compare the coefficients on BADNEWS and GOODNEWS within the partition follow Conrad et al. (2002) using an F-Test of whether the coefficients on BADNEWS and GOODNEWS are equal. The second test examines whether there is a significant change 
in the individual coefficient moving from $\Delta V I X^{-}$to $\Delta V I X^{+}$. To carry out this comparison the following regression is run in a pool:

$$
\begin{aligned}
\text { Ret }= & \beta_{0}+\beta_{1} \text { BADNEWS }+\beta_{2} \text { GOODNEWS }+\beta_{3} \Delta V I X+\beta_{4} \text { BADNEWS * } \\
& \Delta V I X+\beta_{5} \text { GOODNEWS } * \Delta V I X+\varepsilon
\end{aligned}
$$

where BADNEWS/GOODNEWS is deifined as in (1) and $\triangle V I X$ is an indicator variable equal to 1 if the change in the VIX is positive and 0 otherwise. I then use the coefficients $\beta_{4}$ and $\beta_{5}$ to test whether there is a difference between the responses to $B A D N E W S / G O O D N E W S$ across $\triangle V I X^{-}$and $\Delta V I X^{+}$. The third and final test of asymmetry looks at where the difference between $\beta_{1}$ and $\beta_{2}$ in (1) for the $\Delta V I X^{+}$group is different than the $\beta_{1}$ and $\beta_{2}$ in (1) for the $\Delta V I X^{-}$group. To test this difference in differences I use the non-parametric approach of randomization tests. For each iteration I randomly assign firm quarter observations to either the $\Delta V I X^{+}$or $\Delta V I X^{-}$group. I then calculate the difference in differences. This is done 1000 times to create and empirical distribution. The distribution of difference in differences is then ranked and I then observe how many values from the empirical distribution are greater than the actual observed difference in differences.

Although (1) provides the foundational empirical model that is used in the primary test in this paper, I also include a size variable (Size)as a control for potential size bias (Barth and Kallapr, 1996). Size is defined as the natural logarithm of the firm's market value of equity measured at the end of the fiscal quarter. I also include the average level of the VIX over the prior week. Because I use a seasonally adjusted random 
walk as a proxy for news it is possible that intrim events could have adjusted what is really news. If that is the case then this would be picked up in the firm's prior return to the event window. I include the firm prior return over the prior quarter to capture such situations. I also include year fixed effects ${ }^{15}$ and cluster my standard errors on both the firm and time dimension. The inclusion of these variables results in the following empirical model:

$$
\begin{aligned}
& \text { Ret }=\alpha+\beta_{1} \text { BADNEWS }+\beta_{2} \text { GOODNEWS }+\beta_{3} \text { VIX }+\beta_{4} \text { Size }+\beta_{5} \text { Ret }_{\text {Pre }}+ \\
& \text { YearEffects }+\varepsilon
\end{aligned}
$$

\footnotetext{
${ }^{15}$ In results not presented I also include Industry fixed effects and results are robust.
} 


\section{Data}

I collect firm and market securities data from the CRSP database. Financial accounting data along with the earnings announcement dates are obtained from the Compustat quarterly file. I collect analyst data from I/B/E/S. VIX data are collected from the CBOE website beginning in 1986 which is the first year that historical measures of the VIX time series begins. I require firms listed in Compustat to have all needed financial data and quarterly announcement dates.

I further require sample firms to be actively traded over the entire event window. Following Ball, Kothari and Shanken (1993) observations with price less than or equal to \$5 were deleted to minimize the effects of market frictions. To reduce the possibility that findings are driven by illiquidity, following Chordia and Swaminathan (2000) I eliminate any observations that in the week prior to the event window had more than two consecutive days of zero trading, because of the low probability of such events being random. To further reduce the effects of outliers, I delete firms with negative book value of equity (Barth et al., 1998). ${ }^{16}$

To reduce the effects of extreme outliers, following Conrad et al. (2002) firms that have the ratio of earnings to market capitalization greater than one on the announcement day are deleted. All firm level variables are then trimmed at the 1 and 99

\footnotetext{
${ }^{16}$ Untabulated results indicate that inferences are unchanged if each of the restrictions is not imposed. As robustness I also delete all earnings surprises greater than (less than) 0.5 (-0.5) were deleted (Conrad et al., 2002) to control for outliers and inferences are not changed. Also prior research indicates that the responses to earnings is essentially zero for firms reporting negative earnings (Hayn, 1995), for robustness I delete observation with negative level of earnings (Barth, Beaver, and Landsman, 1998) and inferences are not affected.
} 
percentiles. Because of the nature of the BADNEWS and GOODNEWS, BADNEWS is trimmed at the $1^{\text {st }}$ percentile, while GOODNEWS is trimmed at the $99^{\text {th }}$ percentile. I also require that the firm quarter observation have the required variables for all analyses throughout the paper. ${ }^{17}$ The final sample after all of the restrictions are imposed consists of 50,978 firm quarter announcements over the period 1986-2007.

\footnotetext{
${ }^{17}$ The one exception is the sentiment index which I do not require because the time series of the variable ends in 2005.
} 


\section{Primary Results}

\subsection{Descriptive Statistics}

Table 1 provides descriptive statistics for the samples of $\Delta \mathrm{VIX}^{-}$and $\Delta V I X^{+}$. As pointed out in section 2.2 in both samples good and bad earnings news are statistically and economically not different. The mean market adjust return is significantly lower (11 basis point over the three-day window) for the $\Delta V I X^{+}$group which is preliminary evidence of a change in market reactions to news given that the news distributions are the same. In addition to the news variables the univariates in the Table 1 suggests that with the exception of Size, Analyst and $\beta_{\text {Mrkt }}$ the characteristics of the firms in the two samples are indistinguishable both statistically and economically. While Size, Analyst and $\beta_{\text {Mrkt }}$ are statistically different, the economic significance is questionable. For example the economic difference in Size between the two groups comes out roughly to be around \$100 million in market cap. Regardless of the economic significance I control for the size in all regressions and include the other two in a robustness check.

Table 1 also reports two macro-level variables, VIX and Ret $_{\text {Mrkt. }}$ Both of these variables are significant lower for the $\Delta V I X^{+}$group. The significant lower market return is to be expected. Prior research and documented the empirical relation that contemporary increases in the VIX is strongly associated with negative contemporary market returns. This empirical observation is more fully addressed in section 4.2.1. 


\subsection{H1* - Asymmetric Responses to Changes in VIX (Ambiguity)}

Table 2, Column I, presents the initial results from estimations relating to increases $\left(\Delta \mathrm{VIX}^{+}\right)$and decreases $\left(\Delta \mathrm{VIX}^{-}\right)$in VIX prior to the earnings report. The reported BADNEWS coefficient for the $\triangle V I X^{+}$partition is 0.9359 and the GOODNEWS coefficient is 0.5997, and both the BADNEWS and GOODNEWS coefficients are significantly different from zero. To test the asymmetry in the coefficients in each group, I first test whether the BADNEWS and GOODNEWS coefficients in each partition are different from each other. As report in Table 2 the 0.3362 difference between the $B A D N E W S$ and GOODNEWS coefficients is significantly different from the other (F-stat of 6.4, p-value $<0.001)$. This first test shows that within the $\Delta V I X^{+}\left(\Delta V I X^{-}\right)$group there is an asymmetric (symmetric) response by the market, responding more (similar) to bad news than good news.

The second test of asymmetry is the test of whether the difference in differences is different between $\triangle V I X$ groups. Using randomization test the 0.3623 difference in differences is significantly different at the 0.01 level. The results from this test provide evidence that there is a difference in the asymmetry between the two groups. This observed difference in asymmetry across increases and decreases in VIX makes it interesting to understand whether the difference in difference is coming about in a manner consistent with the theory. The last test examines the change in the BADNEWS and GOODNEWS coefficients moving from the decrease in VIX group to the increase in VIX group. The analysis in Table 2 column I shows that there is a significant increase in the BADNEWS coefficient when moving from the decrease in VIX environment to an 
increase in VIX environment. This is consistent with investors placing more weight on bad news. The second part of the test shows that the GOODNEWS coefficient while not statistically significant is decreasing when moving from the decrease in VIX group to the increase in VIX group. The decrease in the GOODNEWS coefficient is also consistent with the theory of ambiguity place less weight on the good news.

To check the robustness of the results in column I, I also include a control variable for the information environment and distress. As an information environment proxy I include the number of analysts (Analyst) that cover the firm prior to the earnings announcement. Analyst is calculated by counting the number of analyst reported in the I/B/E/S database making forecasts for the current quarterly earnings announcement over the prior quarter. If there are no forecast or the firm is not found in $\mathrm{I} / \mathrm{B} / \mathrm{E} / \mathrm{S}$ I assign the value of zero for the firm quarter observation. To control for distress I include the firm's market-to-book ratio (MTB). Column II in Table 2 reports the coefficients from the regression after the inclusion of MTB and Analyst. Results are consistent with those found in column I.

To examine whether the effects of changes in VIX on the response to earnings news extends to the magnitude of VIX changes in addition to the sign of changes, I rank changes in VIX into quintiles and estimate (3) for each of the quintiles. The coefficients for the estimation by quintile are plotted in Figure 2. As a point of reference, the mean change in VIX in the $3^{\text {rd }}$ quintile is not statistically nor economically different from zero, while the mean change for the $2^{\text {nd }}\left(4^{\text {th }}\right)$ quintile is significantly less (greater) than zero. 
The plots of the coefficients show that essentially the BADNEWS and GOODNEWS coefficients move together for decreases in VIX but then the coefficients begin to diverge as VIX increases. Figure 2 also shows that it is only for the extreme increases in VIX that there is an asymmetry in the response to earnings news as indicated by the solid markers. These two results are important because it shows that not all increases in VIX have a similar impact on market responses to earnings news. A relatively small change in VIX does not imply a change in ambiguity. Instead the data suggest that it is only in the extreme increases in VIX that seem to capture the ambiguity shocks.

The findings in Table 2 along with findings in Figure 1 allow me to first reject the null of $\mathrm{H}_{1} \mathrm{a}^{*}$ and fail to reject $\mathrm{H} 1 \mathrm{~b}^{*}$ which is consistent with the ambiguity predictions. In particular, holding signal realization constant, following increases in VIX there is an asymmetric response to information i.e., the market weights bad news more than good news. And that this increasing (decreasing) weight on bad (good) news is monotonic in increasing VIX environments. However, following a decrease in VIX, the weights on good and bad news are equal. Thus, ambiguity shocks change investors' decision making process consistent with maxmin utility theory.

\subsection{Alternative Explanations}

Table 2 provides primary evidence that following increase (decrease) in VIX immediately prior to the earnings news window. However there are plausible alternative explanations that I will examine below. Specifically I investigate and attempt to rule out leverage effects and volatility feedback effects. I then address three additional alternative 
explanations: the torpedo effect, state-risk and investor sentiment. To attempt to rule out these explanations I change my empirical design and adopt the following regression model:

$$
\begin{aligned}
\text { Ret }= & \alpha_{0}+\alpha_{1} \Delta V I X+\alpha_{2} \text { BADNEWS }+\alpha_{3} \text { GOODNEWS }+\alpha_{4} \Delta V I X * \\
& \text { BADNEWS }+\alpha_{5} \text { DVIX } * \text { GOODNEWS }+\alpha_{6} \text { Controls }+\alpha_{7} \text { Controls * } \\
& \text { BADNEWS }+\alpha_{8} \text { Controls } * \text { GOODNEWS }+\varepsilon
\end{aligned}
$$

where $\Delta V I X$ is an indicator variable equal to 1 if the two-day change in the VIX immediately preceding the event window is positive, and 0 otherwise. The primary interest in (4) are two-fold, first the signs on $\alpha_{4}$ and $\alpha_{5}$ where the prediction would be $\alpha_{4}>0$ and $\alpha_{5}<0$. The second interest is whether $\alpha_{4}+\alpha_{2} \geq \alpha_{5}+\alpha_{3}$, if $\alpha_{4}+\alpha_{2}>$ $\alpha_{5}+\alpha_{3}$ then I can interpret the results as evidence that increases in the VIX lead to asymmetric response after controlling for other potential factors that may create asymmetry in the response to bad and good news.

\subsubsection{Leverage and Feedback Effects}

Prior literature has long been interested in the empirical observation of asymmetric volatility (Black, 1976 and Christie, 1982), where conditional variance of next periods returns are negatively correlated with the current period return. Often the literature attributes this phenomenon to one of the following: leverage effects (Black, 1976; Christie, 1982; Schwert, 1989; Duffie, 1995), volatility feedback (French, Schwert, and Stambaugh, 1987; Campbell and Hentschel, 1992) or a combination of both (Bekaert 
and $\mathrm{Wu}, 2000 ; \mathrm{Wu}, 2001)$. One potential concern is that the asymmetric responses documented in Table 2 are a manifestation of the asymmetric volatility phenomenon.

Bekaert and $\mathrm{Wu}$ (2000) provide a unified framework that allows one to consider both the leverage and volatility feedback effects at the firm level. Their framework is based off to assumptions: first, the CAPM holds and second, the documented empirical observation that volatility is persistent. The primary result that comes from their paper is that market level bad (good) news leads larger (smaller) negative correlation between contemporaneous returns and conditional volatility at the firm level through strong asymmetry in conditional covariances. While I find this as a plausible explanation for the observed asymmetries between contemporaneous returns and conditional variances, I believe it would not predict the documented asymmetrical responses to earnings news shown in Table 2 because of the nature of my research design and controls.

A key feature of my research design is that I measure my change in the VIX prior to the event window in which I cumulate firm returns. The above mentioned feedback explanation only speaks to contemporaneous events, all asymmetric volatility effects under the CAPM framework should be instantaneously impounded into the contemporaneous price. In order for the effects to persist into the next period would imply some sort of market frictions where participants were unable to adjust price accordingly, but by requiring my sample to only include more liquid firms (i.e. stock price above \$5 and no zero trading days) this explanation seems less plausible. While conceptual is seems implausible that volatility feedback explains my results in include as 
controls both the contemporaneous market return ( Ret $\left._{m r k t}\right)$ measured from $t-3$ thru $t+1$. I also include the firm's market beta $\left(\beta_{m r k t}\right)$ and the firms leverage ratio (Lev).

While my research design address concerns about asymmetric volatility, the potential for firm specific leverage effects to be present. Earnings announcements do provide news to investors (Ball and Brown, 1968; Beaver, 1968), depending on whether the news is good or bad the leverage (hence the risk) could change. Such an explanation though for the observed asymmetric response to earnings is doubtful primarily because such firm specific asymmetries should be observed also following a decrease in VIX which is not found in the documented results in Table 2. Still with the inclusion of Lev this effect should be controlled for.

Results after controlling for the leverage and feedback effects by including Ret $_{m r k t}$ , $\beta_{m r k t}$, and Lev are presented in Table 3. Consistent with predictions the incremental sign on $B A D N E W S^{*} \triangle V I X$ is positive and significant, indicating that more weight being placed on bad news in following an increase in VIX compared to following a decrease in VIX. The GOODNEWS* $\triangle V I X$ coefficient is negative but not statistically significant at the 0.05 level. I test the asymmetry between good and bad news by using the total bad news coefficient (BADNEWS $+B A D N E W S * \triangle V I X)$ and the total good news coefficient $\left(G O O D N E W S+G O O D N E W{ }^{*} \triangle V I X\right)$. Results indicate that also consistent with predictions investors place significantly more weight on bad news than good news after experiencing an increase in VIX, i.e. (BADNEWS+BADNEWS* $\Delta V I X) \quad>$ $($ GOODNEWS+GOODNEWS* $\triangle V I X)(\mathrm{p}$-value $<0.01)$. 


\subsubsection{Torpedo Effect}

Skinner and Sloan (2002) document during earnings announcements unlike low market-to-book firms, high market-to-book firms experience more extreme responses to bad earnings news than good earnings news. The results are attributed to overoptimistic expectational errors (Lakonishok, Shleifer and Vishny, 1994) and these are errors by investors are corrected at the subsequent earnings announcement through the earnings news. This empirical finding has been coined by the literature as the 'torpedo effect'. For this explanation to plausible it would have to assume that increases in VIX partition firms in a way that increased the market-to-book for all firms. As shown in Table 1 the MTB for both increases and decreases are the same both statistically and economically. Under this observation if the 'torpedo effect' is driving the asymmetric results found I Table 2 following an increase in VIX, the same effect would be seen following a decrease in VIX. So ex ante knowing the results in Tables 1 and 2 it would seem unlikely that effect is being driven by the market-to-book effect ('torpedo effect').

While it seems implausible that the market-to-book effect is driving the results I control for the market-to-book effect by including in (4) an indicator for high/low market-to-book and interact it with the bad and good earnings news. The results of this specification are presented in Table 4 column 1. After controlling for the effects of MTB the incremental coefficient on BADNEWS* $\triangle \mathrm{VIX}$ is positive and significant at the $<0.01$ level, while the GOODNEWS* $\triangle$ VIX coefficient is negative but statistically insignificant. Also a test of the differences in the total good and bad news coefficients 
shows that following an increase in VIX investors place significantly more weight on bad news than on good news at the 0.01 level after controlling for MTB.

\subsubsection{State Risk:}

Another alternative explanation for the observed asymmetry in the response to earnings news is that changes in VIX are capturing changes in states or state risk. In this section I test to see if the observed asymmetry can be attributed to state risk. Veronesi (1999) analyses a rational expectations model which includes an unobservable random state variable. By introducing a random state risk parameter into the denominator of the pricing function, Veronesi (1999) shows that risk averse Bayesian investors react more to bad news than good news when they ex ante believe they are in a good state. In addition, when investors believe ex ante they are in a bad state they react proportionately more to bad news than good news because observed good news in the bad state increases the risk that investors are in a good state. Thus, the Veronesi (1999) model predicts that investors respond the most to bad news in good states and respond the least to good news in bad states.

Although Veronesi (1999) models an aggregate market phenomenon, Conrad et al. (2002) adapts the model to the firm-level and empirically test whether the aggregate market state affects responses to firm-specific earnings news. As a proxy for the state of the market, Conrad et al. (2002) constructs a market P/E ratio every month and sorts firms by the market $\mathrm{P} / \mathrm{E}$ ratio. They provide evidence that during high market $\mathrm{P} / \mathrm{E}$ regimes investors respond more to bad news the good news, which is consistent with Veronesi (1999). 
Because the state risk argument also provides an asymmetry prediction, the asymmetric results following an increase in VIX might be attributable to state risk. However, note that the Veronesi (1999) model predicts the asymmetry in market response manifests during 'good states'. ${ }^{18}$ Following Conrad et al. (2002), I re-estimate (2) including a control for the state of the economy, the market P/E ratio. I construct the ratio as follows. First, using the last available quarterly earnings number for month $t$ and the current shares outstanding as of month $t$, I construct earnings-per-share for each firm in each month $t$. Then using the newly constructed EPS and each firm's price as of month $t$ I compute the market P/E as follows:

$$
\operatorname{Market} \frac{P}{E_{t}}=1 /\left[\sum_{i=\{1, N t\}} w_{i t}\left(\frac{E P S_{i t}}{\text { Price }_{i t}}\right)\right]
$$

$w_{i t}$ is the value of firm $I$ relative to the total market value of firms available in the sample month $t$.

Once the time series of Market P/E ratios are computed I compute the moving 12 month average of Market P/E. I then take the difference between each month’s Market $P / E$ and the 12 month moving average and call the difference - Diff $P / E_{M r k t}$. Conrad et al. (2002) classifies high (low) Diff P/E as good (bad) states. I include Diff P/E in (4) as both a main effect and interacted with BADNEWS and GOODNEWS. ${ }^{19}$

Results reported in the second column in Table 4 indicate that inclusion of the Diff P/E variable does not eliminate the asymmetric (symmetric) response following an

\footnotetext{
${ }^{18}$ Under the ambiguity model, the asymmetric response manifests following an increase in VIX. It is not clear why increases in VIX would imply that the economy is in a 'good state'.

${ }^{19}$ The variable Diff $P / E_{\text {Mrkt }}$ is included in the regression as both continuous and an indicator variable. The results presented use a continuous variable of Diff $P / E_{M r k t}$. In results not tabulated Diff $P / E_{\text {mrkt }}$ is ranked high low in for the time series
} 
increase (decrease) in VIX. In particular, results in the second column of Table 4 report that, after controlling for state risk, the incremental BADNEWS* $\triangle V I X$ (GOODNEWS* $\triangle V I X)$ coefficient is $0.3377(-0.0708)$ and is statistically significant (insignificant). Moreover the total there is significant asymmetry (i.e., large response to the bad news than the good news) in the total coefficients at the $<0.01$ level.

\subsubsection{Investor Sentiment:}

The final potential explanation for the observed asymmetry in the response to earnings news is that $\Delta$ VIX captures shifts in investor sentiment, and not changes in ambiguity. Prior literature has posited investor sentiment explains over- and under reactions to information. ${ }^{20}$ Baker and Wurgler (2006) empirically investigate the effects of investor sentiment in the cross-section of returns using an index created from the various sentiment proxies. They document that when sentiment is high assets are overpriced, and when sentiment is low assets are under priced. Using the measure developed by Baker and Wurgler (2006), Mian and Sankaraguruswamy (2008) show that when sentiment is high (low) investors respond significantly more (less) to good than bad news. ${ }^{21}$ Thus, investor sentiment also produces asymmetry in investor reactions to news. However, unlike the asymmetry induced by ambiguity, investor sentiment asymmetry obtains in both high and low sentiment regimes, and overreactions to bad news in low sentiment regime flip to overreactions to good news in high sentiment regime. This

\footnotetext{
${ }^{20}$ Recently, Caskey (2008) uses an ambiguity framework to explain the over- and under reaction phenomenon as a function of ambiguity-averse investors preferring aggregate information to disaggregated information.

${ }^{21}$ Livant and Petrovits (2008) study reactions to earnings announcements and accruals in different sentiment regimes and find that holding firms with extreme good news during pessimistic sentiment periods earns higher excess returns than holding good news firms in optimistic sentiment periods.
} 
contrasts with the maxmin framework where asymmetry is only observed following increases in VIX where bad news is weighted heavier than good news.

To control for investor sentiment, I re-estimate (4) including the Baker and Wurgler $(2006,2007)$ index $\left(B W_{-} \text {Index }\right)^{22}$ at the beginning of the month of the announcement and interact it with the both the bad and good news coefficients in my regression. ${ }^{23}$ The index is based on six measures of investor sentiment: NYSE share turnover, number of IPOs, closed-end fund discount, first day returns on IPOs, dividend premium, and share of equity issues in total debt and equity issues. To control for business cycles, Baker and Wurgler (2006, 2007) regress each of the six measures on growth in the industrial production index, consumer durables, consumer nondurables and consumer services. After running the first stage regression, the index is computed as the first principle component of the residuals from the first stage regression. As before, I construct an indicator variable based on above and below median $B W_{-}$Index and interact it with BADNEWS and GOODNEWS. Because the index only extends through 2005, my sample is limited to a shorter time period.

The last column in Table 4 shows that the inclusion of an investor sentiment proxy, much like the other alternative explanations, does not affect asymmetric inferences. Specifically increases in VIX lead the market to respond to bad and good news differently, placing more weight on the bad than the good.

\footnotetext{
${ }^{22}$ As alternative proxies for investor sentiment I use the put/call ratio and the consumer sentiment index. Untabulated findings indicate inferences are robust to both of these additional measures of investor sentiment.

${ }^{23}$ I also take the measurement at the end of the month that results are robust.
} 
To summarize the results in this section I find that after controlling for alternative explanations (i.e., leverage effects, feedback effects, market-to-book effects, state-risk, and investor sentiment), the asymmetric response to bad and good news following an increase in VIX is robust. On a final point, in Table 4 in each of the specifications none of the interaction effects are significant for the alternative explanation variables. This is a concern because of potential inadequacy of the controls. To examine this re-estimate all of the regressions in Table 4 and exclude on VIX related variables. In unreported results I am able to replicate prior findings providing support for the validity of the controls. 


\section{Ambiguity Susceptibility}

I next examine whether some firms are more susceptible than others to the effects of ambiguity. As mentioned in section 2, it is plausible that the effects of ambiguity would be more pronounced for firms that have underlying earnings processes that are highly connected to the macro-environment. Examining differential susceptibility to the effects of ambiguity shocks in the cross-section gets at the idea that some firms have a greater potential to experience the effects of an ambiguity shock than others because of the underlying wealth generating process of the firm and its connection to the macro factors.

To investigate this possibility, I test for cross-sectional variation in market responses to earnings information based on what I term ambiguity susceptibility characteristics. Specifically, I examine two attributes: the firm's underlying earnings process as captured by earnings betas (Beaver, Kettler and Scholes, 1970) and a firm's return co-variation with changes in VIX (Ang et al., 2006). Because the measured ambiguity (i.e., VIX) relates to macro- or general ambiguity, it is possible that the effects of such ambiguity would be more pronounced for firms for which the underlying earnings process is highly tied to the macro environment, i.e., firms with high earnings betas, and firms whose stocks co-vary the greatest with changes in VIX.

I conduct my cross-sectional tests by splitting firms into different groups based on their ambiguity susceptibility characteristics. First, I compute earnings betas following Beaver, Kettler and Scholes (1970). Specifically I construct for each firm in the sample 
an earnings surprise beta based on the prior 20 quarters by estimating the following regression model:

$$
U E_{i t}=\alpha_{0}+\beta_{\text {MktEarn }} M r k t U E_{-i t}+\gamma_{\text {ind }} \text { IndUE }-i t+\varepsilon_{i t}
$$

where $U E$ is unexpected earnings seasonally adjusted for firm $i$ in quarter $t$. $U E$ is then regressed on the on the average unexpected earnings for the market (not including firm $i$ ) and the average unexpected earnings for the two-digit sic industry to which firm $i$ belongs (excluding firm i). I require that there be at least five other firms in an industry for it to be included. Both the market and industry metrics are measured contemporaneously at time $t .{ }^{24}$ To compute the firms' earnings beta, $\beta_{M k t E a r n}$ and $\gamma_{\text {ind }}$ are summed together. ${ }^{25}$ I create a dichotomous variable every quarter, where firms above the median are coded 1 and termed high $\beta_{\text {Earn }}$ and firms below the median are coded 0 and termed low $\beta_{\text {Earn }}$.

My second ambiguity susceptibility characteristic is a firm’s return co-variation with changes in VIX. Following Ang et al. (2006), I use daily data obtained from the CRSP daily database over a twenty-day period ending ten days prior to the event window and estimate the following two factor model:

$$
\left(\text { TotalRet }_{i t}-r f_{t}\right)=\alpha_{0}+\beta_{\text {mrktv }}\left(m r k t_{t}-r f_{t}\right)+\beta_{\Delta V I X} \Delta V I X_{t}+\varepsilon_{i t}
$$

\footnotetext{
${ }^{24}$ The earnings betas are constructed based on equally weighting firms when computing industry and market averages. Untabulated findings based on value weights indicate no change in inferences.

${ }^{25}$ In untabulated results I construct the earnings beta only using $\beta_{\text {MktEarn }}$ and inference do not change.
} 
The above model is a returns market model with the addition of the $\Delta V I X_{t}$ term. $\Delta V I X_{t}$ is defined as the one-day change in VIX measured contemporaneously with returns ${ }^{26}$. $\beta_{\triangle V I X}$ can then be interpreted as a measure of a firm's sensitivity or susceptibility to the effects of changes in ambiguity or to changes in the VIX.

I predict that there will be cross-sectional variation in the asymmetric response to earnings information following changes in VIX. Specifically, I predict that for firms where the underlying earnings process has a large systematic component and for firms with high $\beta_{\triangle V I X}$, the effects of changes in ambiguity will be larger. On the other hand, following decreases in VIX, there should be symmetric responses regardless of the firm's susceptibility to ambiguity.

Table 5 and Table 6 provide the earnings beta and $\beta_{\Delta V I X}$ results. Table 5 shows that consistent with my predictions, the asymmetric response by the market obtains only for firms that have a large systematic component to their earnings process. Following an increase in VIX, the market response to bad news (0.9371) is significantly greater than the response to good news (0.5410) for firms with High $\beta_{\text {Earn }}$. For all other groups, the within group response to bad and good earnings news is statistically indistinguishable. Table 5 further points out that the difference in differences between $\Delta \mathrm{VIX}^{+}$and $\Delta \mathrm{VIX}^{-}$ (0.4408) is only significant (at the 0.05 level) within the high $\beta_{\text {Earn }}$ group. Moreover for the high $\beta_{\text {Earn }}$ group this change in difference is driven by a significant increase in the bad news coefficient. This result suggests that in the cross-section, ambiguity susceptibility varies with a firm's earnings betas.

\footnotetext{
${ }^{26}$ Untabulated results based on the sensitivity of two-day changes results in no change in inferences.
} 
Results in Table 6 collaborates the evidence found in Table 5. Results in Table 6 are attained by first partitioning $\beta_{\Delta V I X}$ into high and low, and then partitioning the observations by increases and decreases in VIX. I then estimate the model (3) for each of the $\beta_{\Delta V I X} / \Delta V I X$ groups. The key observation in Table 6 is that the asymmetric response to bad and good earnings news is only found in the high $\beta_{\triangle V I X}$ group following an increase in VIX. Taken together, the results in Table 5 and 6 are consistent with the idea that firms with greater sensitivity to market-wide events are more susceptible to the effects of macro-ambiguity shocks. 


\section{Trading Volume and the Bid-Ask Spread}

\subsection{Trading Volume}

The underpinning of the ambiguity hypothesis is that ambiguity-averse investors lack the relevant information to form unique priors. This section explores this idea more fully by examining whether the lack (presence) of information exacerbates (mitigates) the asymmetric effects of ambiguity. To test the effect of information, I use the presence or lack of trading volume (both firm specific and market wide) during the earnings announcement event window. Prior research has shown that trading volume is associated with information arrival (Beaver, 1968). Using the maxmin framework Dow and Werlang (1992) and Epstein and Schneider (2007) provide theoretical motivation for the relation between ambiguity and trading volume/market participation. ${ }^{27}$

Dow and Werlang (1992) use a special case of the maxmin framework to examine how ambiguity affects investors' decision to participate in the market. They show that the lack of information (ambiguity) about the correct data-generating process creates a wedge between the price agents are willing to go long in an asset (ask price) and the price

\footnotetext{
${ }^{27}$ Billot, Chateauneaf, Gilboa, and Tallon (2000) also directly examine the relation between ambiguity and trading volume. Billot et al. (2000) use the maxmin framework of Gilboa and Schmeidler (1989) to address trading under ambiguity, specifically with regard to agreement and disagreement among traders. Under the typically Bayesian framework investors only trade if there is disagreement on probabilities between investors. Billot et al. (2000) suggest that unlike the Bayesian model of agree/disagree, a model of ambiguity has shades of grey where ambiguity-averse investors may not agree in the sense of having the same set of possible priors, but not disagree in the sense they are willing to take bets against each other. Billot et al. (2000) shows that in a multiple priors (maxmin) framework, if ambiguity-averse investors have at least one prior in common, then there is an absence of betting. Bewley (2002) also provides a model of trading under ambiguity which uses the concept of 'inertia' instead of the maxmin model and finds similar results.
} 
agents are willing to go short (bid price). This increased spread reduces the incentives for ambiguity-averse agents to participate in the market.

Epstein and Schneider (2007) extend Dow and Werlang (1992) to an intertemporal setting and investigate how changes in ambiguity effect market participation Epstein and Schneider (2007) show that an increase in ambiguity leads ambiguity-averse investors to away from market participation. This trend away from market participation reverses as the ambiguity shock is resolved. That is, following an increase in ambiguity the market initiates a learning process and to some extent resolves ambiguity through the gathering or revelation of ambiguity relevant information. This implies that the observed behavior of ambiguity-averse traders after increases in ambiguity will depend on how quickly and completely they discover the missing information that is the underlying driver of ambiguity. In the context of my study, after an increase in VIX it is possible that there will be no asymmetric responses to bad and good news because the missing information implied by the increase in VIX is quickly discovered and traded on immediately. In this case, we would observe symmetric responses to earnings news and high trading volume following an increase in VIX. On the other, if missing information is not quickly discovered, we would observe asymmetric responses to bad and good news and low trading volume (low participation from ambiguity-averse traders).

As another motivation for looking at the effects of volume on the asymmetric responses Easley and O’Hara (2009) show that when there are both Bayesian (i.e., ambiguity neutral) investor and ambiguity adverse investors non-participation in risky assets by the ambiguity adverse investor makes arbitrage impossible by the Bayesian investors even if they have the missing information. If low trading volume is associated 
with non-participation by ambiguity investors then one would again expect the asymmetric effect only to be observed in the low volume sub-partition given an increase in ambiguity.

To investigate the relation between ambiguity and trading volume, I examine responses to bad and good news earnings news within partitions formed by classifying firms on the basis of abnormal trading volume during the earnings announcement window. That is, I first partition firms on whether VIX increased or decreased just prior to the earnings announcement. Then, within each of these VIX partitions, I further partition firms into observed high and low abnormal volume over the three-day event window. I predict that the observed asymmetry in bad and good news responses will be most evident in the increase in VIX, low abnormal volume partition. The intuition is that following an ambiguity potential shock, if volume represents information arrival, then such information-based trading will resolve ambiguity and mute the asymmetric response to news. $^{28}$

One of the concerns with using raw volume is potential size effects (Chordia and Swaminathan, 2000). To eliminate these effects, I use turnover instead of trading volume, and moreover I use abnormal turnover $(A b V o l)$. To construct the $A b V o l$ measure, I first compute the firm's average turnover (AvgVol). AvgVol is computed over fourteen contiguous trading days ending five trading days prior to the first quarterly announcement in firm i's industry in the current fiscal quarter. This 'average' period is chosen to

\footnotetext{
${ }^{28}$ While an increase in VIX potentially reflect ambiguity it is not possible to distinguish whether the lack of an asymmetric response is attributable to resolution of ambiguity or the absence of ambiguity from the start. Therefore I interpret the high volume results with caution.
} 
mitigate the effects of other news distorting the firm's normal or average turnover. Therefore over this period a firm's average turnover is computed as follows:

$$
\text { AvgVol }_{i t}=\frac{1}{14} \sum_{s=-14}^{-1} \log \left[\left[\frac{\text { Sharetraded is }_{\text {SharesOutstanding is }}}{\text { Shat }}\right]+0.00000255\right]
$$

where Sharestraded is the total numbers of firm i's shares traded on day $s$, and ShareOutstanding is the total number of shares outstanding for firm $i$ on day $s$. Following prior research a small constant is added on to avoid taking the log of zero. In a similar manner I compute the cumulative abnormal turnover, or AbVol, for the event window, $t-1$ to $t+1$ where $t$ is the quarter earnings announcement. Specifically AbVol is calculated in the following manner:

$$
\operatorname{AbVol}_{i t}=\sum_{t=-1}^{1}\left[\log \left[\left[\frac{\text { Sharetraded }}{\text { St }}_{\text {SharesOutstanding }}^{i t}\right]+0.00000255\right]-\text { AvgVol }_{i t}\right]
$$

I then rank firm quarter observations by $\mathrm{AbVol}$, creating a dichotomous variable equal to 1 (0) for firm quarter observation that is above (below) the median. The new dichotomous variable is referred to as $\mathrm{AbVol}_{\mathrm{HIGH}}$ for firm quarters above the median and $A b V l_{L O W}$ for firm quarters below the median.

$\mathrm{AbVol}$ can be characterized as a relative ranking among firms, but my prediction should hold with a more general measure of volume. As a more general measure of volume, I compute the abnormal market trading volume during the three-day event window. Unlike $A b V o l$, abnormal market volume ( $A b M V o l)$ is not a turnover measure but instead using raw volume. AbMVol is calculated as follows:

$$
\text { AbMVol }_{i t}=\sum_{t=-1}^{1}\left[\text { MarketVolume }_{t}-\text { AvgMarketVolume }_{t}\right]
$$


where MarketVolume is the total number of share traded in the S\&P 500 on day $t$. AvgMarketVolume is the average number of shares traded on the S\&P 500 over the period $t-40$ to $t-20 .^{29}$ I again create a dichotomous variable equal to 1 (0) for firm quarter earnings announcement windows where there is $A b M V o l$ above (below) the median. The new dichotomous variable is referred to as $A b M V o l_{H I G H}$ for firm quarters above the median and $A b M V o l_{L O W}$ for firm quarters below the median.

Table 7 reports the results of the primary prediction on trading volume. Using abnormal turnover as a proxy for the presence of information, I find that for firms that experience low abnormal turnover (lack of relevant information) over the event window show a strong asymmetric response, with a bad news coefficient of 0.7624 and a good news coefficient of 0.2538 . Both coefficients are statistically different from zero and are statistically different from each other (difference of 0.5086 with a p-value $<0.001$ ). Also, consistent with my prediction, firms that experience high abnormal turnover (relevant ambiguity information is present) have symmetric responses to bad and good news. ${ }^{30}$

Tests on the difference in differences for each volume sub-group shows that there is an increase in the asymmetry for only the $\mathrm{AbVol}_{\text {Low }}$ sub-group when going from $\Delta V I X^{-}$ to $\Delta V I X^{+}$. The difference goes from 0.0437 to 0.5086 which is an increase in the difference between BADNEWS and GOODNEWS moving from $\Delta V I X^{-}$to $\Delta V I X^{+}$of 0.4650 (p-value < 0.01). Moreover, the test of changes in the BADNEWS and

\footnotetext{
${ }^{29}$ The window over which I estimate AvgMarketVolume is arbitrary, untabulated results indicate that inferences are the same when using different time windows to calculate AvgMarketVolume.

${ }^{30}$ As mentioned above an alternative explanation for the high volume result is that there never was ambiguity present in the increase in VIX. Again as mentioned above whether ambiguity was resolved or never present the basic inference is similar i.e., no ambiguity - no asymmetric response.
} 
GOODNEWS coefficients show that in addition to a significant increase (0.3123, p-value $<0.05)$ in the BADNEWS coefficient there is a significant decrease $(-0.1526$, p-value < $0.05)$ in the GOODNEWS coefficient.

Table 8 present the results on the market abnormal volume split. Similar to the $\mathrm{AbVol}$ analysis, the asymmetric response is only present in the low market volume group following an increase in VIX. Specifically for a low abnormal market volume announcement following an increase in VIX the BADNEWS coefficient is 1.2792 and the GOODNEWS coefficient is 0.7363 . Both the BADNEWS and GOODNEWS coefficients are significantly different from zero and are also significantly different from each other. Similar to the $A b V o l$ analysis the additional test of asymmetry collaborate this finding. Table 7 and Table 8 together provide preliminary evidence of a link between ambiguity and trading volume.

Finally, to further explore the effects of ambiguity shocks on decision making I revisit the earnings beta cross-sectional results. In Tables 7 and 8 we see that the lack of volume exacerbate the effects of ambiguity, while Table 5 results indicate that ambiguity responses vary cross-sectionally based on differences in earnings betas.. This suggests that the asymmetry found in Table 5 would only be present in low volume periods following increase in VIX. To test this prediction I sort observations on earnings beta and on $\mathrm{AbVol}$ and then re-estimate the analysis for each of the subgroups. ${ }^{31}$ Table 9 presents the results of the analysis. The asymmetric response is contained only in one group $\left(\triangle V I X^{+} /\right.$High $\left.\beta_{\text {Earn }} / A b V o l_{\text {Low }}\right)$ where the BADNEWS coefficient is 0.8333 and the reported GOODNEWS coefficient is 0.1563 . Again both coefficients are statistically

\footnotetext{
${ }^{31}$ In unreported results I use $\mathrm{AbMVol}$ instead of $\mathrm{AbVol}$ and inferences are the same.
} 
greater than zero and statistically different from each other. Results in Table 9 provide further evidence that there is an important link between shocks in ambiguity and observed trading volume.

\subsection{Bid-Ask Spread}

Dow and Werlang (1992) predict that, in addition to ambiguity reducing market participantion, ambiguity shocks will increase the observed bid-ask spread. Camerer and Weber (1992) also suggest that any shock in ambiguity would result in increased bid-ask spreads. To test the effects of changes in ambiguity on the bid-ask spread I use the following empirical design:

$$
\begin{gathered}
\text { BidAskSpread }=\alpha_{0}+\beta_{1} \Delta V I X+\beta_{2} V I X+\beta_{3} E x U E+\beta_{4} \text { LnPrice }+ \\
\beta_{5} \text { AvgSpread }+\beta_{6} \text { AbVol }+\varepsilon
\end{gathered}
$$

where BidAskSpread is the average daily bid-ask spread for the firm over the three day event window around the earnings announcement. I use two different $\Delta V I X$ variables (11). The first is an indicator set to 1 if the two day change in VIX prior to the event window is a positive value and 0 otherwise. The second measure, ExVIX is an indicator variable set to 1 if the change in VIX is in the top decile of the change in VIX distribution and 0 otherwise. I use the $E x V I X$ measure because as shown in Figure 2 the extremes is where there is more ambiguity potential. VIX is the average level of the VIX over the prior week to the event window. Because Ng (2007) shows that an extreme earnings surprises affect the bid-ask spread, I include EXUE as a control for the effect. ExUE is an indicator variable set to 1 if the firm's $U E$ (defined above) is ranked in the top quintile of the distribution of $U E$, and 0 otherwise. I include LnPrice, which is the natural logarithm 
of the average price over the event window. I calculate AvgSpread by taking the firm's average bid-ask spread over the prior month to the earnings announcement. I also include AbVol which is defined as the abnormal turnover for the firm over the event window.

Table 10 presents the results on the effects of ambiguity on the bid-ask spread using only an indicator for increases and decreases in VIX. The estimate coefficient for a generic increase in VIX increases the average bid-ask spread over the three day window by 8 basis points. Table 10 also reports the estimates again ExVIX. Again the estimated coefficient on ExVIX is statistically significant and the economic magnitude is around 23 basis points. Both results in Table 10 provide evidence consistent with Dow and Werlang (1992). 


\section{Conclusion}

The focus of this paper is to test empirically if changes in ambiguity affect investors' decision making process consistent with prior theoretical predicts and experimental research. Using changes in VIX as an empirical proxy for ambiguity, I find that following an increase in VIX there is a significant asymmetric response to earnings news. Specifically I find that investors weight bad earnings news more heavily than good earnings news. On the other hand I find that following a decrease in VIX investors weight bad and good earnings news symmetrically.

I find that my asymmetric (symmetric) result following increases (decreases) in VIX is robust to controls for investor sentiment and state risk. The observed asymmetric response following an increase in ambiguity and symmetric response following decrease in ambiguity is consistent with prior theories of ambiguity (Epstein and Schneider, 2008; Hansen and Sargent, 2008) and experimental results (Ellsberg, 1961).

In addition, I also find that the effects vary in the cross-section by firm characteristics that make a firm more susceptible to the effects of an ambiguity shock. I find that the asymmetric response is more pronounced for firms that have underlying earnings processes that have a large systematic component. I also find that firms with returns that are more sensitive to change in VIX are more susceptible to the effects of changes in ambiguity.

I also investigate the interplay between trading volume and the observed asymmetric response to earnings news. Using abnormal trading volume (both firm- 
specific and market-wide) as an ex post proxy for information arrival, I find that for firms that experience low (high) levels of volume after an increase in ambiguity, the observed asymmetric response is exacerbated (mitigated). This results is suggestive of a link between ambiguity, information and trading volume. As a final test I document evidence that ambiguity shocks lead to increased bid-ask spreads consistent with predictions by Dow and Werlang (1992).

In this paper I provide large scale empirical evidence that changes in ambiguity affect how investors process the same information consistent with both experimental and theoretical predictions. These results provide insights into the fundamental workings of complex capital markets. The results also suggest a fundamental economic reason for observed asymmetric responses to accounting information. 


\section{Table 1}

\section{Sample Descriptive Statistics}

$\Delta V I X^{+}\left(\Delta V I X^{-}\right)$is coded as a 1(0) if the change in the VIX index measured over the two day prior to the announcement window is positive (negative). RET is the cumulative market adjust return over the three day earnings announcement window (t-1 to $t+1)$, where the market is the return on a value weighted market portfolio. Unexpected earnings $(U E)$ is calculated using a seasonally adjusted random walk $\left[\left(\mathrm{EBIT}_{\mathrm{t}-4}-\right.\right.$ $\mathrm{EBIT}_{\mathrm{t}}$ /Average Assets] BadNews is computed as the firm's UE multiplied by an indicator variable equal to 1 if the unexpected earnings are less than 0 and 0 otherwise. GoodNews is constructed in the same manner as BadNews with the exception that $U E$ is multiplied by an indicator variable that equals 1 if unexpected earnings are greater than 0 and 0 otherwise (Conrad et al., 2002). VIX is the average level of the VIX index the week prior to the event window. Size is the natural logarithm of the firm's market value of equity measured at the end of the quarter. Ret $_{\text {pre }}$ is the firm's cumulative abnormal return computed over the quarter prior to the earnings announcement. $M T B$ is the market-to-book ratio measured at quarter end. Analyst is the number of analyst following the firm during the quarter. AbVol is the is calculated as $A b V o l_{i t}=\sum_{t=-1}^{1}\left[\log \left[\frac{\text { SharesTraded }}{\text { SharesOut }}+0.00000255\right]_{t}-\log \left[\left[\frac{\text { ShareTraded }}{\text { ShareOUt }}\right]_{\text {est }}+0.00000255\right]\right]$ where est is the ten day trading period ending five trading days prior to the first quarterly earnings announcement for the industry in which firm $i$ is a part of. Lev is the firm's leverage, computed as total debt over total assets as of the end of the quarter. $\beta_{M r k t}$ is defined as the firm's beta from a regression of firm returns on market returns computed over the prior twenty days leading up to the event window. Persistence is defined as the coefficient from a seasonally adjusted AR(1) regression over a twenty quarter rolling window ending the quarter prior to the earnings announcement. $\beta_{E a r n}$ is defined by first regressing a firm's $U E$ and the Markets $U E$ and Industry $U E$, where the market and industry $U E$ are calculated excluding firm $i$. The coefficients are the market and industry variables are then summed together. The regression is run over a twenty quarter rolling window ending on the prior quarter. Ret $_{M r k t}$ is the market return computed over the window $\mathrm{t}-4$ to $\mathrm{t}+1$.

\begin{tabular}{|c|c|c|c|c|c|}
\hline \multirow[b]{2}{*}{ Variables } & \multicolumn{2}{|c|}{$\Delta \mathbf{V I X}^{-}$} & \multicolumn{2}{|c|}{$\Delta \mathrm{VIX}^{+}$} & \multirow{2}{*}{$\begin{array}{c}\text { Difference } \\
\Delta \text { VIX }^{+}-\Delta \mathrm{VIX}^{-}\end{array}$} \\
\hline & Mean & StdDev & Mean & StdDev & \\
\hline Ret & 0.0049 & 0.0487 & 0.0038 & 0.0488 & $-0.0011 * * *$ \\
\hline BadNews & -0.0017 & 0.0036 & -0.0016 & 0.0036 & 0.0000 \\
\hline GoodNews & 0.0060 & 0.0078 & 0.0060 & 0.0076 & 0.0000 \\
\hline$V I X$ & 20.3811 & 7.9896 & 19.3395 & 6.8652 & $-1.0416 * *$ \\
\hline Size & 7.1053 & 1.5142 & 7.0753 & 1.5221 & $-0.0300 * *$ \\
\hline Ret $_{\text {Pre }}$ & 0.0105 & 0.2110 & 0.0133 & 0.4363 & 0.0027 \\
\hline MTB & 2.4111 & 1.5911 & 2.4341 & 1.6268 & 0.0230 \\
\hline Analyst & 7.5831 & 5.9706 & 7.4267 & 5.9740 & $-0.1564 * *$ \\
\hline AbVol & 1.0531 & 2.2168 & 1.0489 & 2.2264 & -0.0041 \\
\hline Lev & 0.4290 & 0.1762 & 0.4305 & 0.1755 & 0.0014 \\
\hline$\beta_{\text {Mrkt }}$ & 0.8503 & 0.8005 & 0.8164 & 0.8221 & $-0.0340 * *$ \\
\hline Persistence & 0.4941 & 0.4254 & 0.4967 & 0.4308 & 0.0026 \\
\hline$\beta_{\text {Earn }}$ & 0.7657 & 3.2743 & 0.7737 & 3.3670 & 0.0080 \\
\hline $\operatorname{Ret}_{\text {Mrkt }}$ & 0.0102 & 0.0198 & -0.0016 & 0.0238 & $-0.0117 * * *$ \\
\hline
\end{tabular}

**, *** indicate significance at the 0.05 and 0.01 level respectively. 


\section{Table 2}

\section{Investors’ Asymmetric Response to Earnings Surprise under Ambiguity}

The sample period for quarterly earnings announcements is from 1986 to 2007. Return data is collected from CRSP and all firm specific financial data is collected from Compustat. The announcement window is defined as day $t-1$ to $t+1$ and the window is centered on the quarterly earnings announcement. The dependent variable Ret is defined as the cumulative abnormal return over the event window ( $t-1$ to $t+1)$ where $t$ is the earnings announcement date. $\Delta V I X^{+}\left(\Delta V I X^{-}\right)$is coded as a $1(0)$ if the change in the VIX index measured over the two day prior to the announcement window is positive (negative). For all other variable definitions see Table I. Year fixed effects are included with the standard errors clustered both along the firm and time dimension.

\begin{tabular}{|c|c|c|c|c|}
\hline \multirow[b]{3}{*}{ Variables } & \multicolumn{4}{|c|}{ Dependent Variable: Ret } \\
\hline & \multicolumn{2}{|c|}{$\mathbf{I}$} & \multicolumn{2}{|c|}{ II } \\
\hline & $\Delta \mathbf{V I X}^{-}$ & $\Delta \mathbf{V I X}^{+}$ & $\Delta \mathrm{VIX}^{-}$ & $\Delta \mathbf{V I X}^{+}$ \\
\hline BadNews & $0.6357 * * *$ & $0.9359 * * *$ & $0.6549 * * *$ & $0.9715 * * *$ \\
\hline GoodNews & $0.6619 * * *$ & $0.5997 * * *$ & $0.6975 * * *$ & $0.6210 * * *$ \\
\hline$V I X$ & -0.0001 & -0.0001 & $-0.0001 * *$ & -0.0001 \\
\hline Size & $-0.0009 * * *$ & 0.0002 & $-0.0010 * * *$ & -0.0002 \\
\hline Ret $_{\text {Pre }}$ & $-0.0113 * * *$ & $-0.0033 * *$ & $-0.0108 * * *$ & -0.0032 \\
\hline MTB & & & $-0.0011 * * *$ & $-0.0009 * * *$ \\
\hline Analyst & & & $0.0002 * *$ & $0.0003 * * *$ \\
\hline $\mathrm{N}$ & 27,188 & 23,790 & 27,188 & 23,790 \\
\hline \multicolumn{5}{|l|}{ Test of Asymmetry } \\
\hline BadNews = GoodNews & 0.0262 & $0.3362 * * *$ & 0.0425 & $0.3505 * * *$ \\
\hline Asymmetry $_{D V I X}=$ Asymmetry $_{U V I X}$ & \multicolumn{2}{|c|}{$0.3623 * * *$} & \multicolumn{2}{|c|}{$0.3931 * * *$} \\
\hline \multicolumn{5}{|l|}{ Test of Changes } \\
\hline BadNews: $\quad \Delta V I X^{-}=\Delta V I X^{+}$ & \multicolumn{2}{|c|}{$0.3001 * *$} & \multicolumn{2}{|c|}{$0.3165 * *$} \\
\hline GoodNews: $\Delta V I X^{-}=\Delta V I X^{+}$ & \multicolumn{2}{|c|}{-0.0622} & \multicolumn{2}{|c|}{-0.0765} \\
\hline
\end{tabular}


Table 3

\section{Alternative Explanations for Investors' Asymmetric Response to Earnings Surprise under Ambiguity: Leverage and Feedback Effects}

The sample period for quarterly earnings announcements is from 1986 to 2007. Return data is collected from CRSP and all firm specific financial data is collected from Compustat. The announcement window is defined as day $t-1$ to $t+1$ and the window is centered on the quarterly earnings announcement. The dependent variable Ret is defined as the cumulative abnormal return over the event window ( $t-1$ to $t+1)$ where $t$ is the earnings announcement date. $\Delta V I X$ is coded as a 1(0) if the change in the VIX index measured over the two day prior to the announcement window is positive (negative). For all other variable definitions see Table I. For the below regression $\operatorname{Ret}_{M r k t}, \beta_{M r k t}$ and Lev are all indicator variables coded $1(0)$ if the value is rank above (below) the median. Year fixed effects are included with the standard errors clustered both along the firm and time dimension.

\begin{tabular}{|c|c|c|}
\hline \multirow[b]{2}{*}{ Variables } & \multicolumn{2}{|c|}{ Dependent Variable: } \\
\hline & Prediction & Ret \\
\hline BadNews & & $0.7779 * * *$ \\
\hline GoodNews & & $0.5443 * * *$ \\
\hline$\triangle V I X$ & & -0.0004 \\
\hline BadNews*AVIX & + & $0.2788 * *$ \\
\hline GoodNews* & - & -0.0271 \\
\hline$V I X$ & & $-0.0001 * *$ \\
\hline Size & & $-0.0004 * * *$ \\
\hline Ret $_{\text {Pre }}$ & & $-0.0050 * *$ \\
\hline Ret $_{\text {Mrkt }}$ & & -0.0010 \\
\hline BadNews* Ret $_{\text {Mrkt }}$ & & -0.2502 \\
\hline GoodNews $^{*}$ Ret $_{\text {Mrkt }}$ & & $0.2173 * * *$ \\
\hline Lev & & $-0.0023 * * *$ \\
\hline BadNews*Lev & & 0.0018 \\
\hline GoodNews*Lev & & $0.1499 * *$ \\
\hline$\beta_{\text {Mrkt }}$ & & 0.0010 \\
\hline BadNews $* \beta_{\text {Mrkt }}$ & & -0.0586 \\
\hline GoodNews $* \beta_{\text {Mrkt }}$ & & $-0.1522 * *$ \\
\hline $\mathrm{N}$ & & 50,978 \\
\hline
\end{tabular}


Table 4

\section{Alternative Explanations for Investors' Asymmetric Response to Earnings Surprise under Ambiguity: Risk and Sentiment}

The sample period for quarterly earnings announcements is from 1986 to 2007. Return data is collected from CRSP and all firm specific financial data is collected from Compustat. The announcement window is defined as day t- 1 to $t+1$ and the window is centered on the quarterly earnings announcement. The dependent variable Ret is defined as the cumulative abnormal return over the event window ( $\mathrm{t}-1$ to $\mathrm{t}+1$ ) where $t$ is the earnings announcement date. $\Delta V I X$ is coded as a 1(0) if the change in the VIX index measured over the two day prior to the announcement window is positive (negative). DiffPE is the difference between each month's $P E$ and the previous 12 month average monthly PE (Conrad et al., 2002). $B W_{-}$Index is the Baker and Wurgler $(2005,2006)$ investor sentiment index for the month of the earnings announcement. For all other variable definitions see Table I. For the below regressionMTB, DiffPE and $B W_{\text {IIndex }}$ are all indicator variables coded 1(0) if the value is rank above (below) the median. Year fixed effects are included with the standard errors clustered both along the firm and time dimension.

\begin{tabular}{|c|c|c|c|c|}
\hline \multirow[b]{2}{*}{ Variables } & \multirow[b]{2}{*}{ Prediction } & \multicolumn{3}{|c|}{ Dependent Variable: Ret } \\
\hline & & Skinner/Sloan & Risk & Sentiment \\
\hline BadNews & & $0.7113 * * *$ & $0.6235 * * *$ & $0.5624 * * *$ \\
\hline GoodNews & & $0.7349 * * *$ & $0.6474 * * *$ & $0.6859 * * *$ \\
\hline$\triangle V I X$ & & -0.0002 & -0.0002 & -0.0002 \\
\hline BadNews*AVIX & + & $0.3377 * * *$ & $0.3401 * * *$ & $0.3910 * * *$ \\
\hline GoodNews*AVIX & - & -0.0708 & -0.0734 & -0.1109 \\
\hline$V I X$ & & -0.0002 & $-0.0004 * *$ & $-0.0003 * * *$ \\
\hline Size & & $-0.0001 * * *$ & $-0.0001 * *$ & -0.0001 \\
\hline $\operatorname{Ret}_{\text {Pre }}$ & & $-0.0049 * *$ & $-0.0050 * *$ & $-0.0047 * *$ \\
\hline MTB & & $-0.0025 * * *$ & & \\
\hline BadNews*MTB & & -0.2351 & & \\
\hline GoodNews*MTB & & -0.0681 & & \\
\hline DiffPE & & & -0.0003 & \\
\hline BadNews*DiffPE & & & -0.0227 & \\
\hline GoodNews*DiffPE & & & 0.0304 & \\
\hline$B W \_I n d e x$ & & & & -0.0004 \\
\hline BadNews*BW_Index & & & & 0.0259 \\
\hline GoodNews*BW_Index & & & & -0.0209 \\
\hline $\mathrm{N}$ & & 50,978 & 50,978 & 46,832 \\
\hline
\end{tabular}

**, *** indicate significance at the 0.05 and 0.01 level respectively. 
Table 5

\section{Ambiguity Susceptibility and Investors' Asymmetric Response to Earnings Surprise under Ambiguity: Earnings Beta}

The sample period for quarterly earnings announcements is from 1986 to 2007. Return data is collected from CRSP and all firm specific financial data is collected from Compustat. The announcement window is defined as day $t-1$ to $t+1$ and the window is centered on the quarterly earnings announcement. The dependent variable Ret is defined as the cumulative abnormal return over the event window ( $t-1$ to $t+1)$ where $t$ is the earnings announcement date. $\Delta V I X^{+}\left(\Delta V I X^{-}\right)$is coded as a $1(0)$ if the change in the VIX index measured over the two day prior to the announcement window is positive (negative). For all other variable definitions see Table I. High (low) $\beta_{\text {Earn }}$ are firm quarter observation where their $\beta_{\text {Earn }}$ is above below the median $\beta_{\text {Earn }}$. Year fixed effects are included with the standard errors clustered both along the firm and time dimension.

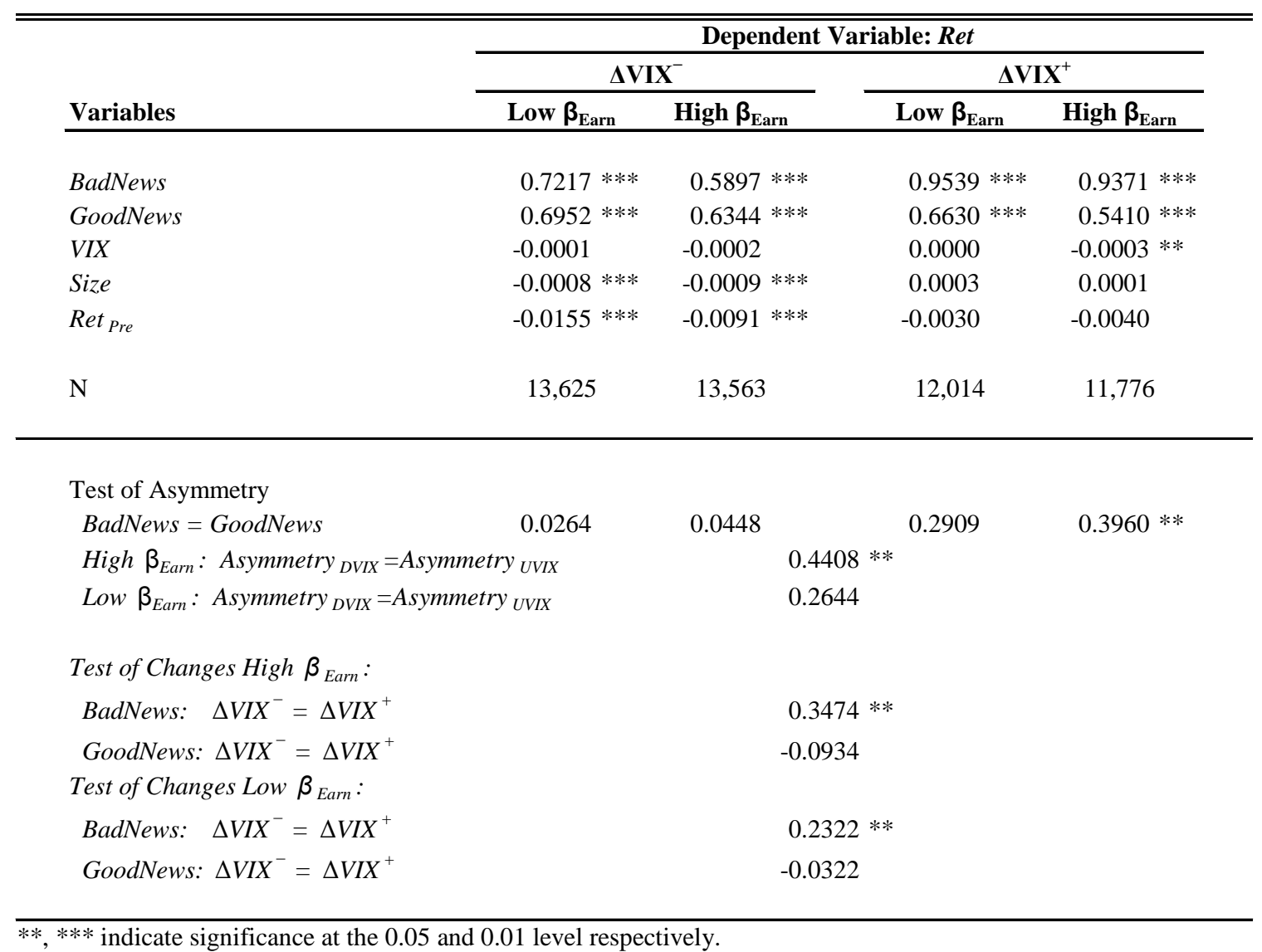


Table 6

\section{Ambiguity Susceptibility and Investors' Asymmetric Response to Earnings Surprise under Ambiguity: VIX Beta}

The sample period for quarterly earnings announcements is from 1986 to 2007. Return data is collected from CRSP and all firm specific financial data is collected from Compustat. The announcement window is defined as day t- 1 to $t+1$ and the window is centered on the quarterly earnings announcement. The dependent variable Ret is defined as the cumulative abnormal return over the event window (t-1 to $t+1)$ where $t$ is the earnings announcement date. $\Delta V I X^{+}\left(\Delta V I X^{-}\right)$is coded as a 1(0) if the change in the VIX index measured over the two day prior to the announcement window is positive (negative). For all other variable definitions see Table I. $\beta_{\Delta V I X}$ is the VIX beta computed by running the following regression Return $_{i t}=\alpha_{0}+\beta_{1} M r k t_{t}+\beta_{\Delta v i x} \Delta V I X_{t}+\varepsilon_{i t}$, where Return is the firm i's excess return for day $t$, Mrkt is the excess market return for day $t$ and $\Delta V I X$ is the daily change in the VIX index. The regression is run over twenty trading days ending ten trading days prior to the event window. Each regression requires a full twenty days. High (low) $\beta_{\triangle V I X}$ are firm quarter observation where their $\beta_{\triangle V I X}$ is above below the median $\beta_{\triangle V I X}$. Year fixed effects are included with the standard errors clustered both along the firm and time dimension.

\begin{tabular}{|c|c|c|c|c|}
\hline \multirow[b]{3}{*}{ Variables } & \multicolumn{4}{|c|}{ Dependent Variable: Ret } \\
\hline & \multicolumn{2}{|c|}{$\Delta \mathrm{VIX}^{-}$} & \multicolumn{2}{|c|}{$\Delta \mathrm{VIX}^{+}$} \\
\hline & Low $\beta_{\Delta V I X}$ & High $\beta_{\Delta V I X}$ & Low $\beta_{\Delta V I X}$ & High $\beta_{\Delta V I X}$ \\
\hline BadNews & $0.6272 * * *$ & $0.6420 * * *$ & $0.8908 * * *$ & $1.0164 * * *$ \\
\hline GoodNews & $0.6736 * * *$ & $0.6541 * * *$ & $0.6454 * * *$ & $0.5815 * * *$ \\
\hline$V I X$ & -0.0002 & -0.0001 & -0.0001 & -0.0002 \\
\hline Size & $-0.0007 * *$ & $-0.0011 * * *$ & 0.0002 & 0.0003 \\
\hline Ret $_{\text {Pre }}$ & $-0.0113 * *$ & $-0.0112 * * *$ & $-0.0186 * * *$ & $-0.0023 * *$ \\
\hline $\mathrm{N}$ & 13,609 & 13,579 & 11,858 & 11,932 \\
\hline \multicolumn{5}{|l|}{ Test of Asymmetry } \\
\hline BadNews = GoodNews & 0.0464 & 0.0121 & 0.2454 & $0.4348 * * *$ \\
\hline \multicolumn{2}{|c|}{ High $_{\Delta V I X}$ : Asymmetry $_{D V I X}=$ Asymmetry $_{U V I X}$} & \multicolumn{2}{|c|}{$0.4469 * *$} & \\
\hline \multicolumn{2}{|c|}{ Low $\beta_{\Delta V I X}$ : Asymmetry $_{D V I X}=$ Asymmetry $_{U V I X}$} & \multicolumn{2}{|c|}{0.2918} & \\
\hline \multicolumn{5}{|c|}{ Test of Changes High $\beta_{\triangle V I X}$ : } \\
\hline BadNews: $\quad \Delta V I X^{-}=\angle$ & \multicolumn{4}{|c|}{$0.3743 * *$} \\
\hline GoodNews: $\Delta V I X^{-}=$ & \multicolumn{4}{|c|}{-0.0726} \\
\hline \multicolumn{5}{|c|}{ Test of Changes Low $\beta_{\Delta V I X}$ : } \\
\hline BadNews: $\quad \Delta V I X^{-}=$ & \multicolumn{4}{|c|}{0.2636} \\
\hline GoodNews: $\Delta V I X^{-}=$ & \multicolumn{4}{|c|}{-0.0283} \\
\hline
\end{tabular}

**, *** indicate significance at the 0.05 and 0.01 level respectively. 


\section{Table 7 \\ The Examination of the Effects of Information (Abnormal Firm Volume) on Investors’ Asymmetric Response to Earnings Surprise under Ambiguity}

The sample period for quarterly earnings announcements is from 1986 to 2007. Return data is collected from CRSP and all firm specific financial data is collected from Compustat. The announcement window is defined as day $t-1$ to $t+1$ and the window is centered on the quarterly earnings announcement. The dependent variable Ret is defined as the cumulative abnormal return over the event window ( $\mathrm{t}-1$ to $\mathrm{t}+1$ ) where $t$ is the earnings announcement date. $\Delta V I X^{+}\left(\Delta V I X^{-}\right)$is coded as a 1(0) if the change in the VIX index measured over the two day prior to the announcement window is positive (negative). For all other variable definitions see Table I. High (low) $\mathrm{AbVol}$ are firm quarter observation where their $\mathrm{AbVol}$ is above below the median $\mathrm{AbVol}$. Year fixed effects are included with the standard errors clustered both along the firm and time dimension.

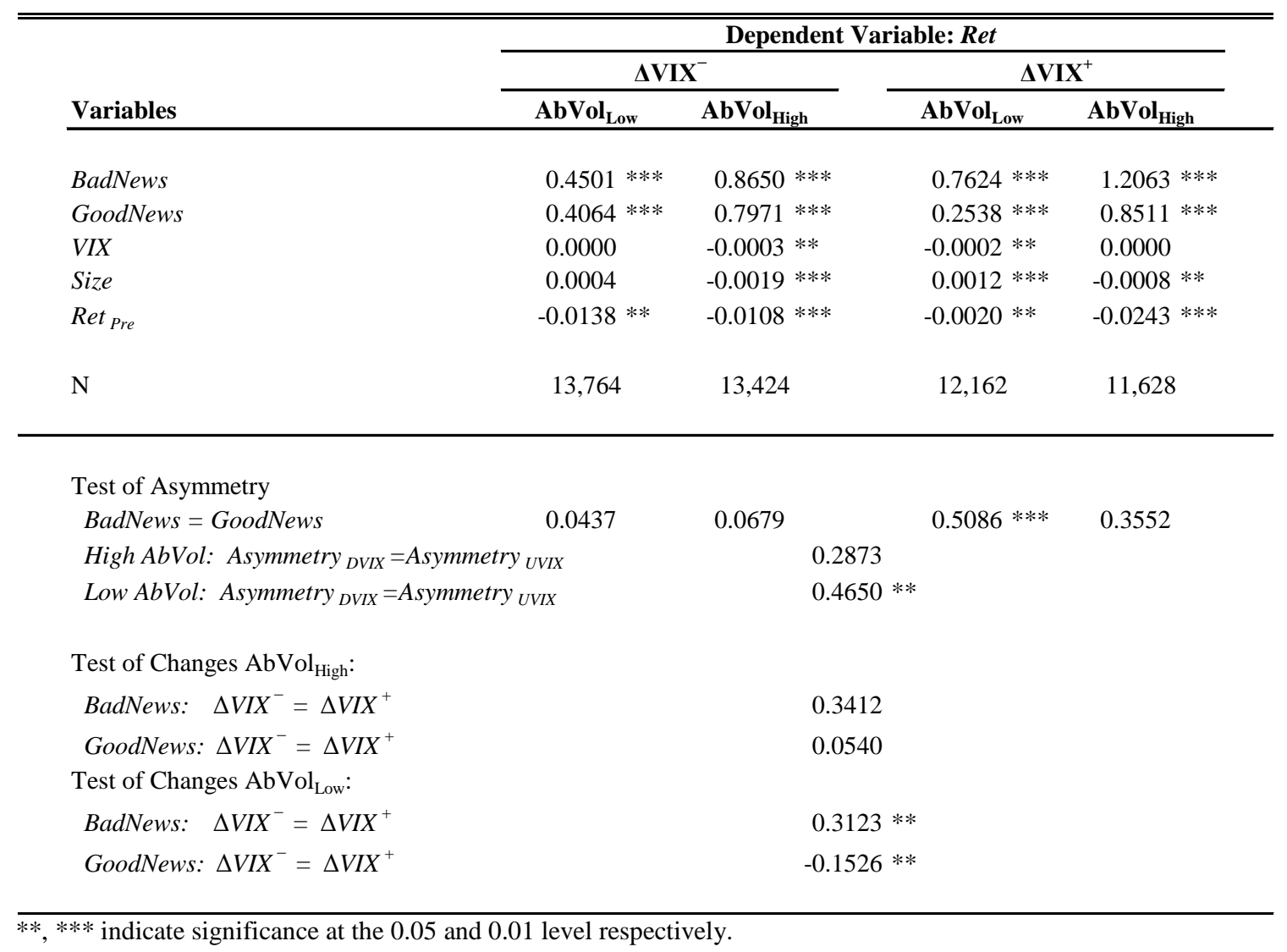




\section{Table 8 \\ The Examination of the Effects of Information (Abnormal Market Volume) on Investors’ Asymmetric Response to Earnings Surprise under Ambiguity}

The sample period for quarterly earnings announcements is from 1986 to 2007. Return data is collected from CRSP and all firm specific financial data is collected from Compustat. The announcement window is defined as day $t-1$ to $t+1$ and the window is centered on the quarterly earnings announcement. The dependent variable Ret is defined as the cumulative abnormal return over the event window ( $\mathrm{t}-1$ to $\mathrm{t}+1$ ) where $t$ is the earnings announcement date. $\Delta V I X^{+}\left(\Delta V I X^{-}\right)$is coded as a 1(0) if the change in the VIX index measured over the two day prior to the announcement window is positive (negative). For all other variable definitions see Table I. High (low) AbMVol are observation where their AbMVol is above below the median AbMVol. Year fixed effects are included with the standard errors clustered both along the firm and time dimension.

\begin{tabular}{|c|c|c|c|c|}
\hline \multirow[b]{3}{*}{ Variables } & \multicolumn{4}{|c|}{ Dependent Variable: Ret } \\
\hline & \multicolumn{2}{|c|}{$\Delta \mathbf{V I X}^{-}$} & \multicolumn{2}{|c|}{$\Delta \mathbf{V I X}^{+}$} \\
\hline & AbMVol $_{\text {Low }}$ & AbMVol $_{\text {High }}$ & AbMVol $_{\text {Low }}$ & AbMVol $_{\text {High }}$ \\
\hline BadNews & $0.7879 * * *$ & $0.5477 * * *$ & $1.2792 * * *$ & $0.8057 * * *$ \\
\hline GoodNews & $0.7585 * * *$ & $0.6251 * * *$ & $0.7363 * * *$ & $0.5608 * * *$ \\
\hline$V I X$ & -0.0001 & $-0.0002 * *$ & -0.0001 & -0.0002 \\
\hline Size & -0.0006 & $-0.0010 * * *$ & 0.0001 & 0.0002 \\
\hline Ret $_{\text {Pre }}$ & $-0.0223 * * *$ & $-0.0096 * * *$ & $-0.0304 * * *$ & $-0.0025 * *$ \\
\hline $\mathrm{N}$ & 9,645 & 17,543 & 7,442 & 16,348 \\
\hline \multicolumn{5}{|l|}{ Test of Asymmetry } \\
\hline BadNews = GoodNews & 0.0295 & 0.0774 & $0.5429 * * *$ & 0.2448 \\
\hline \multicolumn{2}{|c|}{ High AbMVol: Asymmetry $_{D V I X}=$ Asymmetry $_{U V I X}$} & \multicolumn{2}{|c|}{0.3222} & \\
\hline \multicolumn{2}{|c|}{ Low AbMVol: Asymmetry $_{D V I X}=$ Asymmetry $_{U V I X}$} & \multicolumn{2}{|c|}{$0.5135 * *$} & \\
\hline \multicolumn{5}{|c|}{ Test of Changes AbMVol $\mathrm{High}_{\text {: }}$ : } \\
\hline BadNews: $\quad \Delta V I X^{-}=\Delta$ & \multicolumn{4}{|c|}{$0.2580 * *$} \\
\hline GoodNews: $\Delta V I X^{-}=$ & \multicolumn{4}{|c|}{-0.0643} \\
\hline \multicolumn{5}{|c|}{ Test of Changes AbMVol Low: } \\
\hline BadNews: $\quad \Delta V I X^{-}=\Delta$ & \multicolumn{4}{|c|}{$0.4912 * *$} \\
\hline GoodNews: $\Delta V I X^{-}=$ & \multicolumn{4}{|c|}{-0.0222} \\
\hline
\end{tabular}




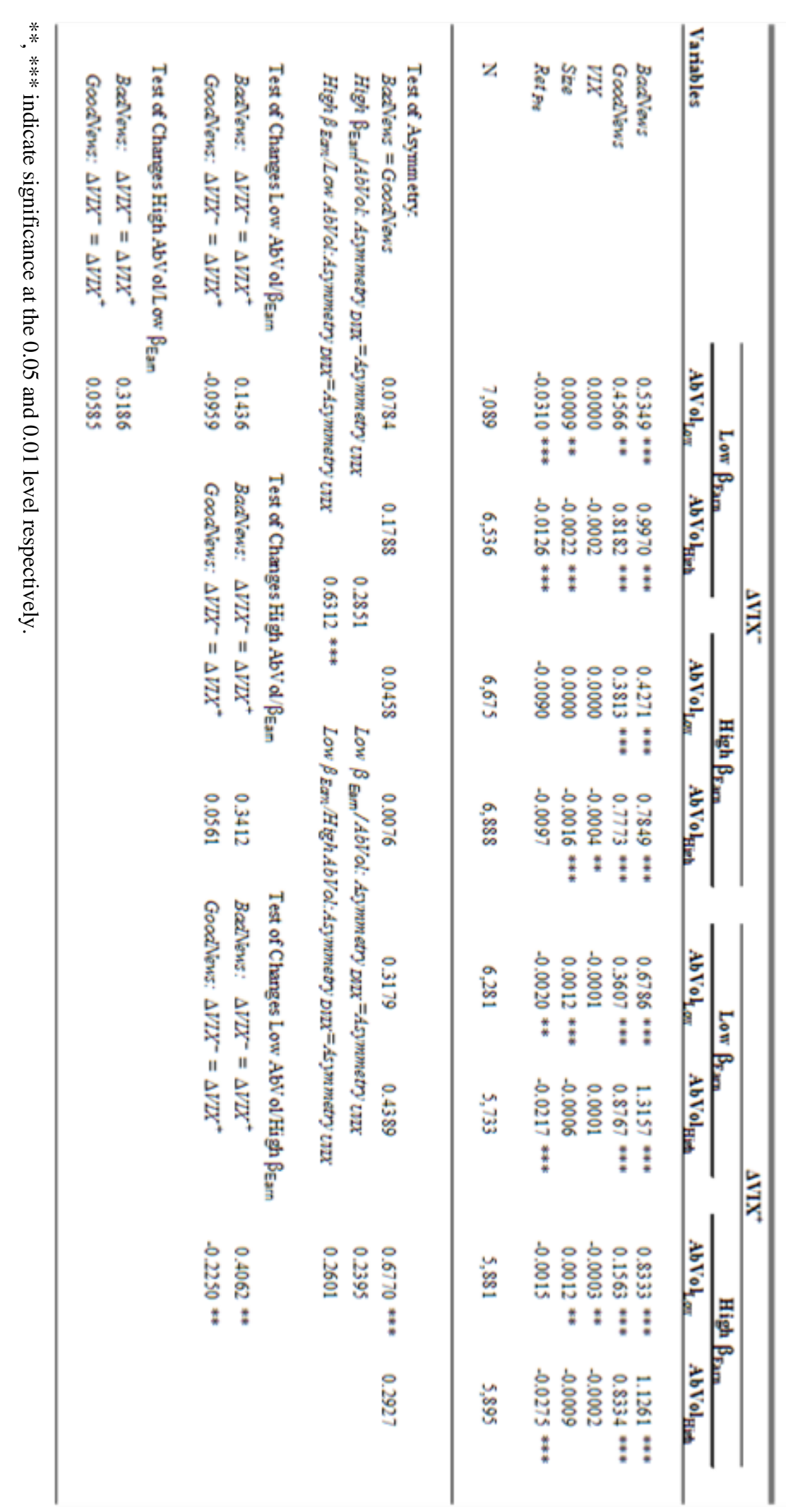

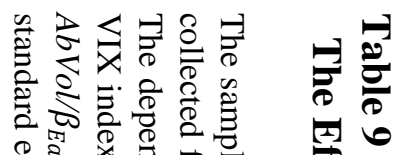

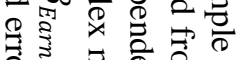

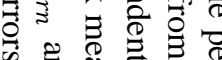

己

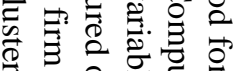

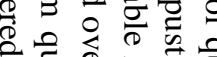

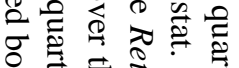

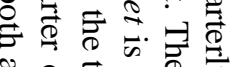

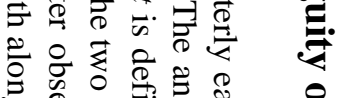

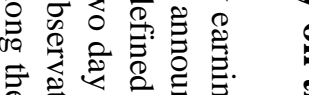

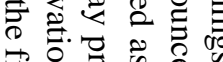

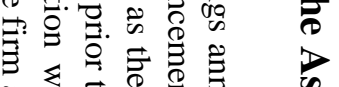

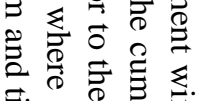

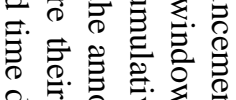

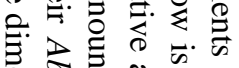

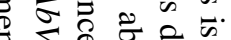

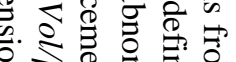

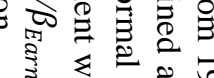

క. $\begin{array}{lll}0 & 0 & 0 \\ 0 & 0 & 0\end{array}$

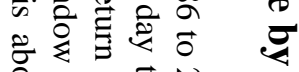

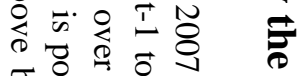

$\sigma$.

芝志吉票

志宫导塄

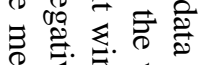

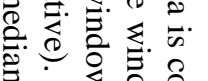

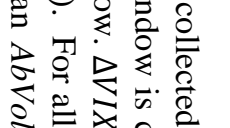

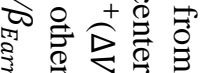

政

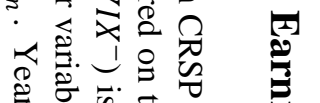

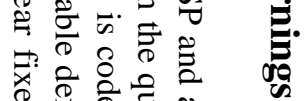

总总总

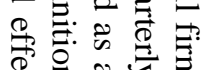

के

क若

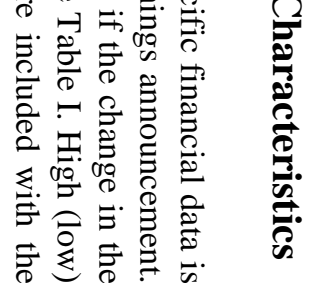




\section{Table 10}

\section{Increases in Ambiguity and the Effect on the Bid-Ask Spread}

The sample period for quarterly earnings announcements is from 1986 to 2007. Return data is collected from CRSP and all firm specific financial data is collected from Compustat. The announcement window is defined as day $\mathrm{t}-1$ to $\mathrm{t}+1$ and the window is centered on the quarterly earnings announcement. The dependant variable is the average bid-ask spread for the event window. $\Delta V I X$ is an indicator variable set to 1 if the change in VIX is positive and 0 otherwise. ExVIX is an indicator variable set to 1 if the change in VIX is in the top decile of the distribution of changes in VIX. ExUE is defined as an indicator variable set to 1 if the firm's $U E$ (defined above) is ranked in the top quintile of the distribution of $U E$, and 0 otherwise. I include LnPrice which is the natural log of the average price over the event window. I also include $A b V o l$ which is defined as the abnormal turnover for the firm over the event window. standard errors clustered both along the firm and time dimension.

\begin{tabular}{|c|c|c|}
\hline Variables & \multicolumn{2}{|c|}{ Dependent Variable: Spread } \\
\hline$\triangle V I X$ & $0.0007 * *$ & \\
\hline EXVIX & & $0.0023 * * *$ \\
\hline VIX & $0.0003 * * *$ & $0.0003 * * *$ \\
\hline ExUE & $0.0028 * * *$ & $0.0028 * * *$ \\
\hline LnPrice & $-0.0045 * * *$ & $-0.0045 * * *$ \\
\hline AvgSpread & $0.6252 * * *$ & $0.6248 * * *$ \\
\hline $\mathrm{AbVol}$ & $0.0032 * * *$ & $0.0032 * * *$ \\
\hline $\mathrm{N}$ & 50,978 & 50,978 \\
\hline $\mathrm{R}^{2}$ & $40.32 \%$ & $40.46 \%$ \\
\hline
\end{tabular}




\section{Figure 1}

\section{Time Series of the VIX and the $\Delta$ VIX (1986 2007)}

Below present the time series of the VIX index for the sample period 1986-2007. The VIX index is collected by the Chicago Board Option Exchange from the 1986 to present. The VIX index is constructed by the Chicago Board Options Exchange (CBOE), and represents the implied volatility of at-the-money option for the S\&P100 index with a maturity of 1 month. Specifically it is calculated from eight S\&P100 index calls and puts and takes into account the American features of the option contracts, discrete cash dividends, and microstructure frictions such as bid-ask spreads. Panel A presents the level of the index whereas Panel B show the times series of the two-day change.

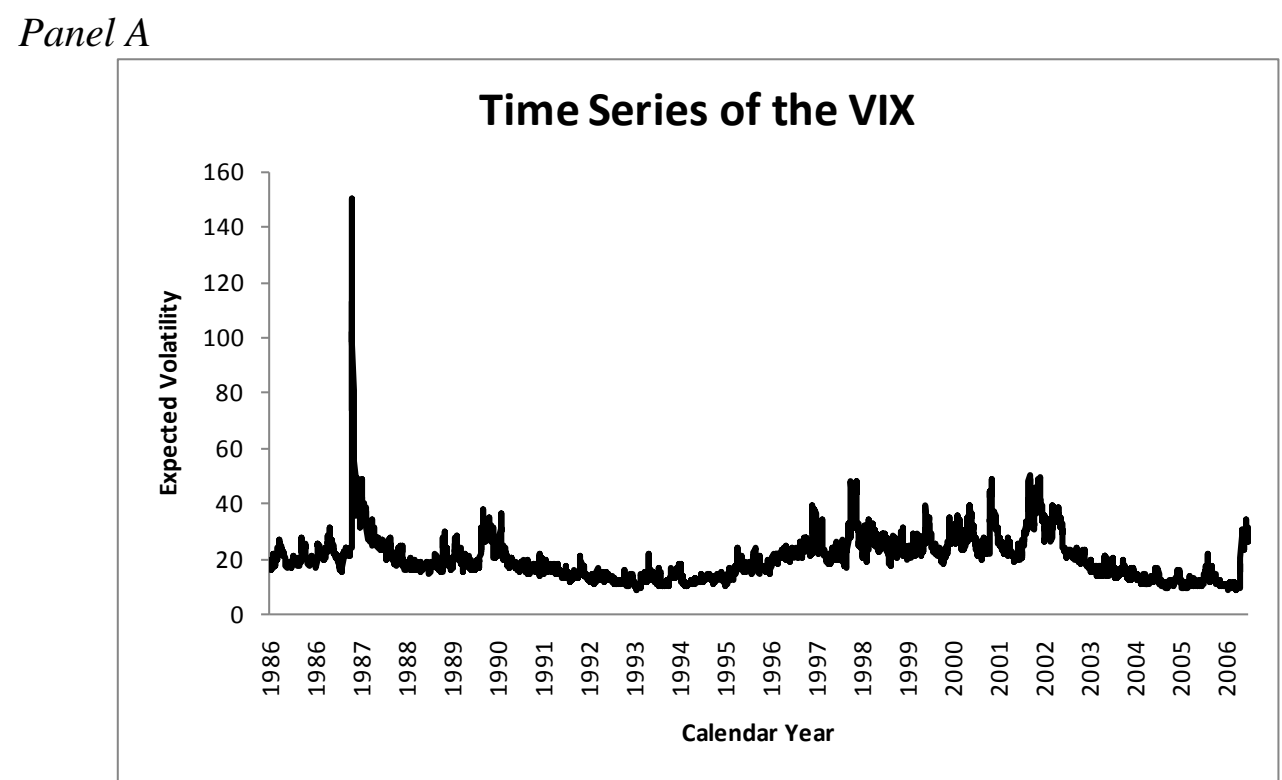

\section{Panel B}

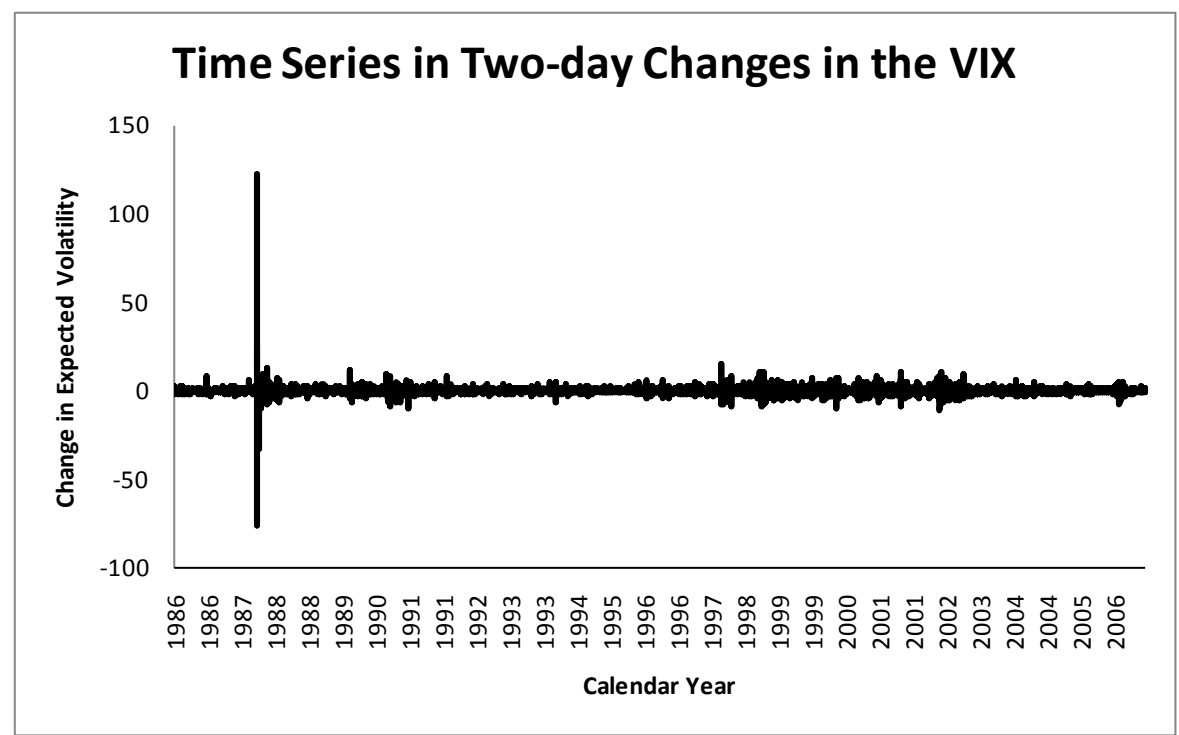




\section{Figure 2}

\section{Plot of GOODNEWS and BADNEWS Coefficients across Quintiles of $\triangle \mathrm{VIX}$}

Below is the plot of the GOODNEWS and BADNEWS coefficients across $\triangle$ VIX Quintiles. The sample period for quarterly earnings announcements is from 1986 to 2007. The announcement window is defined as day -1 to day +1 of the quarterly earnings announcement. The dark line is the BADNEWS or bad news coefficient across quintiles. The lighter line is the GOODNEWS or good news coefficient across quintiles. As an indicator of significant difference a filled box indicates the BADNEWS and GOODNEWS coefficients are significantly different at the 0.01 level.

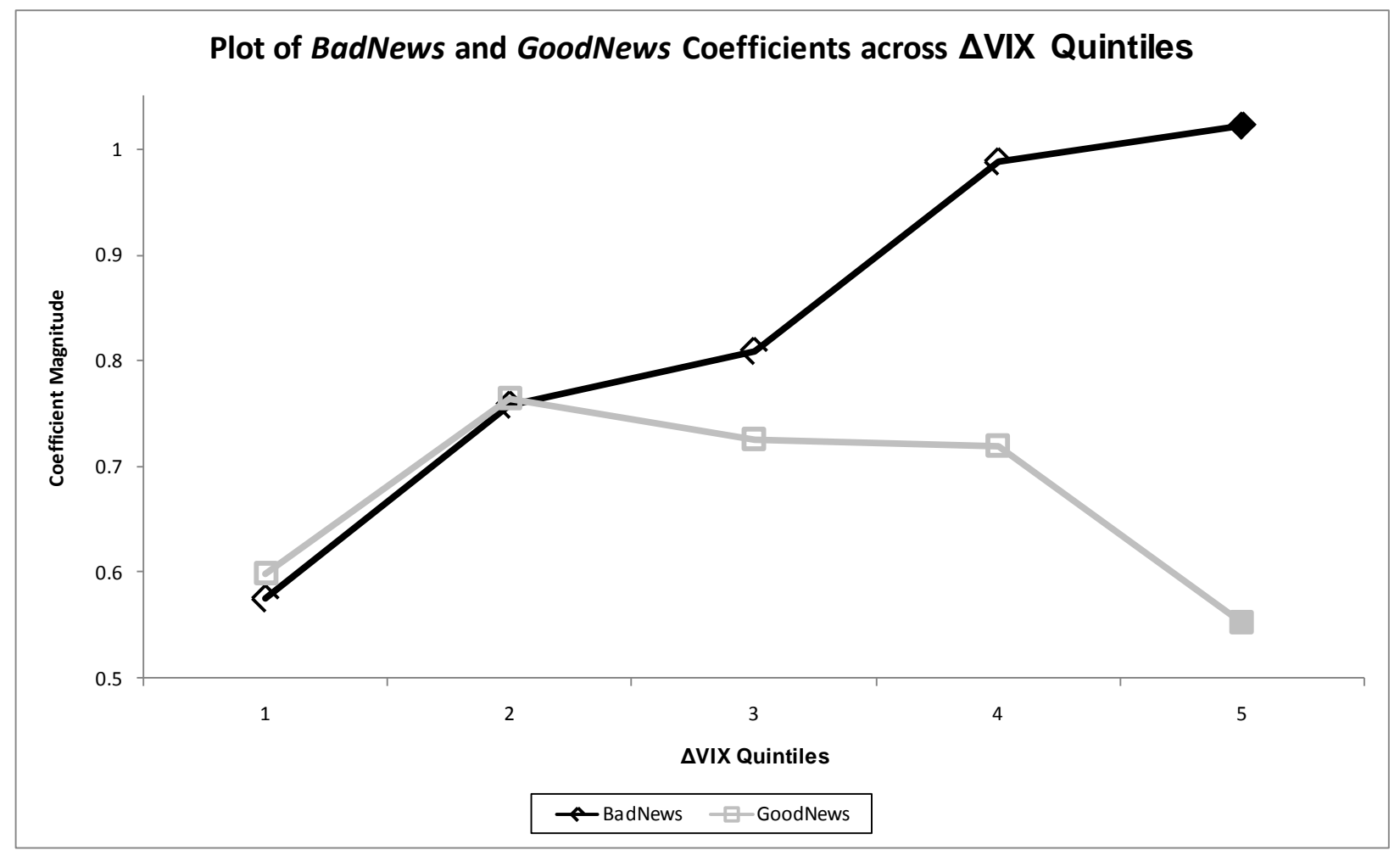




\section{References:}

Anderson, E. W., E. Ghysels, and J. L. Juergens. 2008. “The Impact of Risk and Uncertainty on Expected Returns.” Journal of Financial Economics, forthcoming

Ahn, D.S. 2008. “Ambiguity Without a Stat Space.” Review of Economics Studies 75: 328.

Ang, A., R. J. Hodrick, Y. Xing, and X. Zhang. 2006. "The Cross-Section of Volatility and Expected Returns.” Journal of Finance 61: 259-299.

Ataise, R. K. 1985. "Predisclosure Information, Firm Capitalization, and Security Price Behvior Around Earnings Announcements.” Journal of Accounting Research 23 (1): 21-36.

Ataise, R.K. 1987. "Market of Prediclosure Information: Size and Exchange Effects." Journal of Accounting Research 25(1):168-176.

Baker, M., and J. Wurgler. 2006. "Investor Sentiment and the Cross-Section of Stock Returns.” Journal of Finance 61: 1645-1680.

Baker, M. and J. Wurgler. 2007. "Investor sentiment in the stock market.” Journal of Economic Perspectives 21(2): 129-151.

Ball, R., and P. Brown. 1968. “An Empirical Evaluation of Accounting Income Numbers.” Journal of Accounting Research 6: 159-177.

Ball, R., S. P. Kothari, and J. Shanken. 1993. "Problems in Measuring Portfolio Performance: An Application to Contrarian Investment Strategies.” Journal of Financial Economics 38: 79-107.

Barberis, N., A. Shleifer and R. Vishny. 1998. “A model of investor sentiment.” Journal of Financial Economics 49: 307-343.

Barth, M.E., W.H. Beaver, and W.R. Landsman. 1998. "Relative valuation roles of equity book value and net income as a function of financial health.” Journal of Accounting and Economics 25: 1-34.

Barth, M. E. and S. Kallapur. 1996. "Effect of Cross-Sectional Scale Differences on Regression Results in Empirical Accounting Research.” Contemporary Accounting Research 13: 527-567.

Beaver, W.H. 1968. “The Information Content of Annual Earnings Announcements.” Journal of Accounting Research Supplement 6: 67-92. 
Beaver, W., P. Kettler, and M. Scholes. 1970. "The Association Between Market Determined and Accounting Determined Risk Measures.” The Accounting Review 45: 654-682.

Bewley, T.F. 2002. "Knightian decision theory. Part I.” Decisions in Economics and Finance 25: 79-110.

Billot, A., A. Chateauneuf, I. Gilboa, and J. Tallon. 2000. "Sharing Beliefs: Between Agreeing and Disagreeing.” Econometrica 68: 685-694.

Camerer C. and M. Weber. 1992. "Recent Developments in Modeling Preferences: Uncertainty and Ambiguity.” Journal of Risk and Uncertainty 5: 325-370.

Caskey, J. A. 2008. "Information in Equity Markets with Ambiguity Averse Investors.” Review of Financial Studies, forthcoming.

Chordia, T., and B. Swaminathan. 2000. "Trading Volume and Cross-Autocorrelations in Stock Returns.” Journal of Finance 55: 913-935.

Collins, D., and S. P. Kothari. 1989. “An Analysis of Intertemporal and Cross-Sectional Determinants of Earnings Response Coefficients.” Journal of Accounting and Economics 143-181.

Conrad, J., B. Cornell, and W. R. Landsman. 2002. "When is Bad News really Bad News?” Journal of Finance 57: 2507-2532.

Dennis, P., and S. Mayhew. 2002. "Risk-Neutral Skewness: Evidence form Stock Options.” Journal of financial \& Quantitative Analysis 37: 471-493.

Dow, J. and S. R. C. Werlang. 1992. "Uncertainty Aversion and the Optimal Choice of Portfolio.” Econometrica 60: 197-204.

Drechsler, I. 2008. “Uncertainty, Time-Varying Fear, and Asset Prices.” Working Paper, The Wharton School, University of Pennsylvania.

Easley, D and M. O’Hara, 2008. "Liquidity and Valuation in an Uncertain World.” Working Paper, Cornell University.

Easton, P., and M. Zmijewski. 1989. "Cross-sectional Variation in the Stock Market Response to Accounting Earnings Announcements. Journal of Accounting and Economics 11: 117-141. 
Ellsberg, D. 1961. "Risk, Ambiguity, and the Savage Axioms." Quarterly Journal of Economics 75: 643-669.

Epstein, L. G. and M. Schneider. 2003. "Recursive multiple-priors.” Journal of Economic Theory 113: 1-31.

Epstein, L.G. and M. Schneider. 2007. "Learning under ambiguity.” Review of Economic Studies 74:1275-1303.

Epstein, L. G. and M. Schneider. 2008, "Ambiguity, Information Quality and Asset Pricing.” Journal of Finance 63: 197-228.

Freeman, R.N. and S.Y. Tse. 1992. "A Non-Linear Model of Security Price Response to Unexpected Earnings.” Journal of Accounting Research Autumn: 185-209.

Frisch, D., and J. Baron. 1988. “Ambiguity and Rationality.” Journal of Behavioral Decision Making 1: 149-157.

Gilboa, I. and D. Schmeidler. 1989. "Maxmin Expected Utility with Non-Unique Prior.” Journal of Mathematical Economics 18: 141-153.

Hansen, L. P. and T. J. Sargent. 2008. "Fragile beliefs and the price of model uncertainty.” Working Paper, University of Chicago.

Hayn, C. 1995. "The Information Content of Losses.” Journal of Accounting and Economics 20: 125-153.

Kim, O. and R. E. Verrecchia, 1994, "Market liquidity and volume around earnings announcements.” Journal of Accounting and Economics 17: 41-67.

Knight, F. H. 1921. Risk, Uncertainty and Profit. Boston: Houghton Mifflin Company.

Kormendi, R., and R. Lipe, 1987. “ Earnings Innovations, Earnings Persistence, and Stock Returns.” The Journal of Business 60: 323-345.

Kothari, S. P. 2001. "Capital markets research in accounting." Journal of Accounting and Economics 105-231.

Lang, M.H. 1991. "Time-Varying Stock Price Response to Earnigns Induced by Uncertainty about the Time-Series Process of Earnings.” Journal of Accounting Research Autumn: 229-257.

Livnat, J. and C. Petrovits. 2008. "Investor Sentiment, Post-Earnings Announcement Drift, and Accruals.” Working Paper. 
Mian and Sankaraguruswamy. 2008. "Investor Sentiment and Stock Response to Corporate News.” Working Paper National University of Singapore.

Ng, J. 2007. “Earnings Surprises and Changes in Liquidity.” Working Paper.

Savage, L. J. 1954. The Foundations of Statistics. New York: John Wiley (Second Edition, 1972, New York: Dover).

Skinner, D.J. and R.G. Sloan. 2002. "Earnings Surprises, Growth Expectations, and Stock Returns or Don't Let an Earnings Torpedo Sink Your Portfolio.” Review of Accounting Studies 7: 289-312.

Whaley, R. E. 2000. “The Investor Fear Guage.” Journal of Portfolio Management 26.

Veronesi, R. 1999. "Stock Market Overreaction to Bad News in Good Times: a Rational Expectations Equilibrium Model.” Review of Financial Studies 12: 975-1007 